\title{
El papel de los servicios de interés general en la reforma de la legislación española de régimen local
}

\author{
Casimiro López García \\ Interventor - Tesorero de Administración Local
}

Sumario: 1. DIVERSIDAD DE CONCEPTOS DE SERVICIO PÚBLICO. 1.1. El concepto amplio. 1.2. El concepto estricto.-2. EL SERVICIO PÚBLICO EN LA CONSTITUCIÓN ESPAÑOLA DE 1978. 2.1. Servicio público e iniciativa económica. 2.2. Las misiones constitucionales de servicio público. 2.3. Las obligaciones económicas del poder público en la CE. 2.4. Los servicios mínimos y las actividades o servicios esenciales en la Ley de Bases del Régimen Local. - 3. DISTINCIÓN ENTRE SERVICIO PÚBLICO Y ACTIVIDAD ECONÓMICA DE LOS ENTES LOCALES. 3.1. Criterios de distinción. 3.2. Los problemas de la teoría del servicio público como prestación en monopolio. - 4. LA TEORÍA DEL SERVICIO PÚBLICO EN EL DERECHO COMUNITARIO: DEL TRATADO DE ROMA AL TRATADO DE MAASTRICHT. 4.1. Los servicios de interés económico general. 4.2. El concepto de servicio universal. 4.3. El Servicio de interés económico general en el Tratado de Maastricht. - 5. EL DEBATE SOBRE LA COMPETENCIA LEGISLATIVA DE LA UNIÓN EUROPEA EN MATERIA DE SERVICIOS DE INTERÉS ECONÓMICO GENERAL. 5.1. Libro Verde de la Comisión Europea, de 21 de mayo de 2003, sobre los servicios de interés general. 5.2. La financiación de los servicios económicos de interés general. 5.3. Comunicación de la Comisión Europea al Parlamento Europeo, al Consejo, al Comité Económico y Social y al Comité de las Regiones, de 12 de mayo de 2004: «Libro Blanco sobre los Servicios de Interés General».-6. EL SERVICIO DE INTERÉS GENERAL COMO PRINCIPIO ESENCIAL DE DERECHO COMUNITARIO: EL TRATADO DE LISBOA, DE 13 DE DICIEMBRE DE 2007. 6.1. Tratado de Funcionamiento. 6.2. Protocolo sobre los servicios de interés económico general.-7. LOS EFECTOS DEL TRATADO DE LISBOA SOBRE LA LEGISLACIÓN DE RÉGIMEN LOCAL. 7.1. Principio de subsidiariedad y cláusula de universalidad local. 7.2. El Protocolo de los servicios de interés económico general como canon de constitucionalidad. 7.3. La garantía institucional de la Administración local y los Estatutos de Autonomía. 7.4. Definitiva recepción del concepto de servicio de interés económico general

\section{DIVERSIDAD DE CONCEPTOS DE SERVICIO PÚBLICO}

\subsection{El concepto amplio}

El Servicio Público es una teoría francesa, formulada por la denominada Escuela de Burdeos, cuyo profesor Leon Duguit lo identificó con la total actividad del Estado: «toda actividad cuyo cumplimiento debe ser regulado, asegurado y fiscalizado por los gobernantes, porque el cumplimiento de esa actividad es indispensable para la realización y desenvolvimiento de la interdependencia social y de tal naturaleza que no puede ser asegurada completamente 
más que por la intervención de la fuerza gobernante.» Se proponía un concepto general y abstracto del servicio público que dotase de unidad y consistencia a los distintos significados de servicio público utilizados por el Consejo de Estado francés ${ }^{1}$. Este concepto amplio deja en segundo plano el concepto estricto o concreto de servicio público, utilizado por la legislación administrativa en el siglo XIX, para distinguir aquellas actividades de prestación directa al público de ciertos servicios técnicos que exigen un funcionamiento ordinario y continuo, que se considera indispensable para satisfacer las necesidades colectivas demandadas por la opinión general, del resto de las actividades desplegadas por el poder público.

Esa dualidad de acepciones o conceptos, uno amplio y otro restringido, unida a la obligada planificación estatal de la economía para hacer frente a las necesidades de suministro de armamento en la I Guerra mundial - que modifica para siempre la relación entre política y economía, como tan acertadamente expuso Keynes en su obra «El fin del laissez-faire» ${ }^{2}$ y las convulsiones de la crisis económica mundial de 1929, que obligó a la intervención directa del Estado en economía, terminan por oscurecer las distintas acepciones del servicio público hasta confundirlo con una creciente e imparable actividad económica del Estado ${ }^{3}$. La degradación del concepto será total y absoluta, como certifica ALESSI, al senalar que del servicio público hay tantas definiciones como autores.

Para mayor confusión, la reconstrucción europea de los años 50 del pasado siglo se fundamenta en el ejercicio generalizado de la iniciativa pública en materia económica, que asume sectores industriales completos (carbón, acero, energía eléctrica, telefonía, transportes), fenómenos que ya no pueden explicarse con la ayuda de un concepto amplio de servicio público ${ }^{4}$, e implican el abandono doctrinal del concepto por inservible para explicar las actividades de un Estado $^{5}$ que ha extendido su objeto a las industrias básicas, convirtiéndose en el primer empresario del país; pero que no identifican una función pública su-

\footnotetext{
1 La Doctrina del Conseil d'Etat lo introduce desde el «arrét Blanco», de 1873, como criterio de deslinde y atribución competencial ante la jurisdicción contencioso-administrativa, que se le había delegado por el Gobierno de la III República para excluir la competencia de los Tribunales ordinarios en toda la materia administrativa como una consecuencia de la separación de poderes.

2 John MAYNARD KEYNES: «Ensayos sobre intervención y liberalismo» Biblioteca de Economía. Ed. ORBIS, 1987, Madrid.

3 Tomás Ramón FERNÁNDEZ RODRÍGUEZ: «Del Servicio Público a la liberalización, desde 1950 hasta hoy» RAP, núm. 150 septiembre-diciembre de 1999 (CEPC) MADRID, pág. 58: «Releer ahora la literatura de la época es como chapotear en un terreno pantanoso en el que, además, la neblina no permite distinguir los contornos de las figuras. Cada autor intenta describir como mejor puede lo que ve, pero como no percibe otra cosa que sombras borrosas sin perfiles definidos, lo que acierta a transmitir no es sino una impresión personal, una impresión vaga, por otra parte, que no coincide con las demás sino en su propia vaguedad. COUZINET: «Una expresión equívoca, con la que se arriesga a engendrar las peores confusiones.» WALINE: «sin otro valor que el de una simple etiqueta.»
}

4 CORAIL: «La crise de la notion juridique de service publique», París, 1954.

5 MorAnge: «Le decline de la notion de service publique» Recueil Dajjoz, 1947. 
jeta a un régimen exorbitante o una necesidad pública esencial, sino que sirve para canalizar la inversión hacia los sectores económicos estructurales.

En España, a pesar de las diferencias políticas y del aislamiento del Estado, un examen de la doctrina de la década de 1950 refleja la misma crisis del servicio público. VILLAR PALASí lo definirá como «actividad administrativa de prestación positiva, a través de un servicio técnico, regular y continuo, realizado para y frente al público por una organización pública nomine propio o por delegación ${ }^{6}$, que puede identificarse perfectamente con el concepto técnico de servicio público asistencial de titularidad pública, pero que no puede incluir el nuevo fenómeno de intervención económica dirigida a la producción de bienes materiales que el propio autor identifica como actividad económica directa de «dación de bienes al mercado», que tendrá un desarrollo importante en España a través del Instituto Nacional de Industria, creado a imagen y semejanza del IRI italiano, en $1942^{7}$, que logra consolidar un sector empresarial público (sociedades y empresas públicas) dedicadas de pleno a la actividad mercantil e industrial directa, cuya existencia se pondrá en tela de juicio, a medida que la década de 1980 suprime fronteras a los movimientos de capital y las sucesivas crisis económicas trasladan la producción a los países emergentes. Procesos que hacen inviable mantener un sector público empresarial a pura pérdida ${ }^{8}$.

\subsection{El concepto estricto}

A pesar de su indudable influencia en toda Europa, el sentido globalizador del concepto de Servicio Público francés no tiene recepción en España; el Derecho administrativo español maneja distintos conceptos para explicar las distintas formas como la actividad administrativa satisface el interés general ${ }^{9}$. La doctrina española llega a proponer, junto a la clásica clasificación tripartita de JORDANA DE POZAS (Policía, Fomento y Servicio Público), la citada «dación de bienes al mercado,» que nunca llegó a consolidarse. En España la actividad de fomento ha tenido y tiene gran predicamento doctrinal, legal y práctico; una buena parte del gasto público se gestiona en forma de subvención. En cuanto a

6 J.L.Villar Palasí: «La actividad industrial del Estado en el Derecho Administrativo» RAP, núm. 3, septiembre-diciembre de 1950 (IEP), Madrid.

7 Interpretación que comparte GARCÍA DE ENTERRÍA en «La actividad industrial de los municipios» RAP. Núm. 17, mayo-agosto de 1955.

8 M. DURUPTY «Les privatisations en France», París 1988. GASPAR ARIÑO «El nuevo servicio público», Madrid 1997.

9 Sigue vigente la clasificación propuesta por el Profesor JORDANA DE POZAS: la Administración puede actuar utilizando la coacción (policía), la persuasión (fomento) o facilitando por sí misma las prestaciones necesarias para satisfacer el interés o la necesidad pública en cuestión (actividad de servicio público). Policía (concepto que hunde sus raíces en el viejo ius politiae), fomento y servicio público constituyen las tres formas de la actuación administrativa. 
la actividad de Policía, el continuo incremento de tareas, servicios y funciones públicas le confiere un ámbito creciente, incluso en los servicios liberalizados, sobre los que conserva poderes de control de las actividades y obligaciones de servicio público impuestas en los liberalizados «servicios universales» ${ }^{10}$. Por ende, el concepto de servicio público responde a la acepción concreta de prestación técnica organizada por el poder público para dar respuesta a una necesidad colectiva esencial, que puede definirse con GARRIDO FALLA como «Servicio técnico prestado al público de una manera regular y constante mediante una organización de medios personales y materiales cuya titularidad pertenece a una Administración pública y bajo un régimen jurídico especial». Sus notas esenciales se pueden definir como sigue:

Ha de establecerse como un servicio técnico, que requiere una organización estable y compleja con entidad suficiente para realizar prestaciones concretas a favor del público. No expide actos administrativos: órdenes, licencias, autorizaciones o sanciones; realiza prestaciones técnicas.

Se presta al público con estricta sujeción al principio de igualdad ante la ley. Esta característica de igualdad y generalidad, amén de su precio - habitualmente, político-, sin perjuicio de sus múltiples formas y especialidades, explica la continuidad de su éxito y la creciente e imparable demanda ciudadana, que justifica el incremento continuo de todo tipo de actividades y prestaciones de servicio público en las Comunidades Autónomas y en los Ayuntamientos, que ha llegado al absurdo de crear una sociedad para cada actuación concreta ${ }^{11}$. La tendencia a la personificación de los servicios y a la proliferación de sociedades de servicio público, organismos autónomos, empresas públicas - ahora también fundaciones -, consorcios y convenios entre Administraciones, escapa a los sucesivos intentos de clasificación legal: los artículos 2 y 3 de la Ley 47/2003, General Presupuestaria, reconocen un sector público administrativo, un sector empresarial y un sector fundacional, que se distinguen sólo y exclusivamente por el papel del mercado en su actuación y financiación ${ }^{12}$. Mayor libertad de elección del medio y de la forma de prestación existe en los entes locales $^{13}$, al posibilitar el artículo 85 de la Ley $7 / 85$, cualquier modalidad y sistema de gestión, con la sola limitación de la exclusión de las formas mercantiles para la gestión indirecta para los actos de autoridad, arts. 12 LOFAGE y 85.3 Ley 7/85, de Bases del Régimen Local.

\footnotetext{
10 José Luis LóPEZ MUÑíz «En torno a la nueva regulación de los servicios económicos esenciales en red (a propósito de la nueva Ley de telecomunicaciones y su sistema conceptual)» Vol. col. «El Derecho Administrativo en los umbrales del S. XXI, homenaje al P. D. Ramón Martín Mateo (Vol. III Tirant Lo Blanc), Valencia, 2000.

11 Francisco SOSA WAGNER «La actual encrucijada de los servicios y las empresas públicas locales», pág. 16 y 17. Revista de Estudios Locales, núm. extra, julio de 2007 (COSITAL) Madrid.

12 La misma complicación puede verse en el artículo 3 de la Ley 3/2007, de Contratos del Sector Público.

13 Valentin ESTRADA MERINO «La elección de las formas de prestación de los servicios públicos locales. Revista de Estudios Locales, núm. extraordinario, julio de 2007 (COSITAL) Madrid.
} 
La prestación tiene que ser regular y continua, en correspondencia con el correlativo derecho reconocido a los particulares por un acto del poder legislativo. Sin una prestación estable, segura y continua no existe el servicio público. La regularidad y continuidad son sus notas más características, que explican la modulación del derecho de huelga de sus funcionarios y empleados, y de la libertad de expresión ${ }^{14}$.

La titularidad pública es una nota inherente en la definición; sin que influya en ello la gestión indirecta del servicio, en la técnica de concesión que disocia la titularidad de la gestión, la Administración concede la explotación del servicio (siempre que sea susceptible de explotación económica), pero conserva la titularidad; sin que por ello pueda desentenderse del mantenimiento del equilibrio económico del contrato, ni quede cubierta del riesgo de gestión ${ }^{15}$.

El sometimiento a un régimen jurídico especial, como expresión de la unidad política del Estado, y ejercicio de los principios de igualdad y solidaridad entre todos los ciudadanos en el acceso y sostenimiento de los servicios de interés general, es la nota en mayor crisis, al autorizarse todo tipo de fórmulas para la prestación de los servicios públicos, desde la sociedad privada hasta la fundación. Reconociendo la jurisprudencia penal reciente (SSTS 1292/2000, 68/2003, 1590/2003, 866/2003) un concepto amplio de servicio público: «lo verdaderamente característico y lo que les dota de la condición pública, es la función realizada dentro de un organigrama de servicios públicos» o «cualquier actuación de estas entidades donde exista un interés público responde a ese concepto amplio de función pública». Doctrina que se limita a constatar la realidad palmaria de la completa consolidación de la huida del Derecho administrativo hacia formas societarias privadas en las Leyes de Presupuestos de las Comunidades Autónomas, para evitar la engorrosa gestión pública, que pone todo tipo de frenos y trabas a las fórmulas de libre nombramiento de personal y sujeta la contratación a una intervención estricta ${ }^{16}$. Sin embargo, esta gestión «privada» no excluye en absoluto la utilización de cláusulas exorbitantes, directamente o por medio de técnicas de colaboración, convenios, encomiendas, cesiones, separación del régimen de gestión y de los sistemas de cobros que, cuando se necesita, garantizan el mantenimiento de las prerrogativas públicas, a pesar del traje privado.

Para terminar este breve recorrido por los antecedentes del concepto de servicio público, hay que convenir con Tomás Ramón FERNÁNDEZ RODRÍGUEZ que se trata de un concepto que perdió todo interés para la doctrina científica

14 Artículos 20 y 28.1 CE, SSTC 6/2000, de 17 de enero, y 26/1986, de 19 de febrero.

15 Casimiro LÓPEZ GARCÍA. «El equilibrio económico financiero de la concesión de servicio público: origen, evolución y situación actual». El Consultor de los Ayuntamientos y Juzgados, núm. 15/2004, págs. 2603-2640, Madrid.

16 Art. 3.2 de la ley 30/2007, de 30 de octubre de Contratos del Sector Público. 
mientras las prestaciones sociales básicas del Estado (educación, salud y vejez) no estaban en riesgo y las empresas públicas garantizaban un empleo de por vida. Cuando las políticas neoliberales de los EE.UU. de Ronald Reagan y de la Inglaterra de Margarett Thatcher en la década de 1980 renuevan un neoliberalismo, que pierde fuelle a medida que la crisis financiera norteamericana de 2007 se extiende por el resto del mundo. Lo que pone en primera línea de discusión, en toda Europa y en los EEUU, el debate sobre la teoría del servicio público y sobre el alcance de la actividad económica de los Estados con más pasión que nunca en la doctrina política, económica y jurídica, centrando en buena parte los programas de los partidos políticos y las discusiones parlamentarias sobre las sucesivas leyes, ahora de intervención directa en el mercado y en sistema bancario, ayer privatizadoras de los servicios económicos de interés general en red, y de las compañías energéticas ${ }^{17}$. La fuerza de la crisis es de tal magnitud que ha mitigado la discusión interna sobre las fórmulas de financiación Autonómica, generada en parte por el reconocimiento de un financiación singular para Cataluña en su nuevo Estatuto de Autonomía, aprobado por LO 6/2006.

\section{EL SERVICIO PÚBLICO EN LA CONSTITUCIÓN ESPAÑOLA DE 1978}

\subsection{Servicio público e iniciativa económica}

La Constitución de 1978 establece el concepto de Estado social y democrático de Derecho que impone unas obligaciones específicas a los poderes públicos en aras de la efectividad de la libertad y la participación de todos en la vida económica, social y cultural del país en los artículos 1 y 9.2 del Título Preliminar. La CE impone un concepto esencial de servicio público cuando, a la hora de regular el derecho de huelga, el art. 28.2 alude a la existencia de servicios esenciales que se configuran como un límite al ejercicio del derecho de huelga: «Se reconoce el derecho de huelga de los trabajadores para la defensa de sus intereses. La ley que regule el ejercicio de este derecho establecerá las garantías precisas para asegurar el mantenimiento de los servicios esenciales de la comunidad» ${ }^{18}$.

La configuración constitucional de un concepto de servicio público esencial se completa en el artículo 128.2: «Se reconoce la iniciativa pública en la actividad económica. Mediante Ley se podrá reservar al sector público recursos o

\footnotetext{
17 Sebastián MARTíN-RETORTILlo BAQUEZ. «reflexiones sobre las privatizaciones» Revista de Administración Pública 7, Núm. 144. Septiembre-diciembre 1997 (CEPC) Madrid.

18 La jurisprudencia de nuestro Tribunal Constitucional se ha tenido que pronunciar repetidamente sobre la constitucionalidad del establecimiento de servicios mínimos, especialmente en materia de transportes urbanos, ferrocarriles y aéreos (Sentencias del Tribunal Constitucional de 24 de abril y 17 de julio de 1986).
} 
servicios esenciales, especialmente en caso de monopolio, y asimismo acordar la intervención de empresas cuando así lo exigiere el interés general.» La CE distingue entre iniciativa económica y servicio público, al que identifica con el suministro o la prestación de servicios esenciales con vocación de monopolio. La efectividad de la socialización se sujeta a reserva de Ley «publicatio», como una garantía y un requisito adicional al reconocimiento a la libre iniciativa pública en materia económica ${ }^{19}$. La naturaleza esencial del servicio es la verdadera condición material de la «publicatio», que está a disposición del Tribunal Constitucional, en cuanto pueda oponerse o afectar - la reserva - a los derechos fundamentales que figuran en los artículos 14 a $30 \mathrm{CE}$ o al principio de libertad de empresa del artículo $38 \mathrm{CE}^{20}$. Por el contrario, la iniciativa pública en materia económica (en régimen de libre competencia) no implica reserva a favor del sector público, y sólo está condicionada al interés general y a los principios de eficacia, eficiencia y economía que figuran en los artículos 31.2 y 103.1 CE.

La mera referencia al interés general no es suficiente para establecer servicios públicos ni para nacionalizar recursos ${ }^{21}$, por tratarse de la finalidad general y abstracta de toda actuación pública que enlaza directamente principios de actuación de la Administración Pública del artículo 103 CE: «La Administración Pública sirve con objetividad los intereses generales y actúa de acuerdo con los principios de eficacia... con plena sujeción a la ley y al Derecho»: el interés público está referido directamente en la CE a una gestión eficaz, pero no exige expresamente que resulte un beneficio mayor para la comunidad de la prestación en manos públicas que en manos privadas. La Constitución de 1978 no se limita a una mera declaración de grandes principios, tras asumir los valores del Estado social y democrático de Derecho en el artículo 9, dedica todo el capítulo III del Título I «De los principios rectores de la política y social económica», artículos 39 a 52, a establecer verdaderos mandatos (misiones, en terminología de Derecho comunitario) de servicio público a la Administración Pública, que expresan los valores ideológicos y determinan los contenidos Estado. Lo que impedirá que se queden en meras declaraciones de buenas intenciones; por el contrario, sus mandatos todavía presiden la discusión política y han dirigido la actividad legislativa del Estado y de las Comunidades Autónomas (CCAA) hasta la fecha.

\subsection{Las misiones constitucionales de servicio público}

Los referidos «principios rectores de la política social y económica» expresan los valores de transformación social y participación ciudadana propios del Estado

\footnotetext{
19 Los servicios mínimos del art. 28.2 CE son, en el fondo, una modalidad de las obligaciones de servicio público que se pueden imponer al prestador del servicio universal en Derecho Comunitario

20 SSTC 112/2006, de 5 de abril, y 127/94, de 5 de mayo, sobre acontecimientos deportivos de interés general y derechos de pago de las cadenas de televisión privadas, y sobre la configuración de la televisión como un servicio público.
}

21 STC 247/2007, de 12 de diciembre (Estatuto de Autonomía de Valencia), reserva de recursos hidráulicos. 
que establece la nueva Constitución de 1978, sin los cuales resultaría ilusorio. Su reconocimiento ha obligado a una actuación continuada de los poderes públicos dirigida al apoyo de todos los sectores económicos básicos, y a una actuación continuada de todas las Administraciones para posibilitar el acceso a la cultura, la formación profesional, la inserción laboral; y a desplegar una actividad parlamentaria ingente en materia de vivienda, salud, vejez, ocio, juventud o suelo, medio ambiente, deporte, servicios sociales y en materia cultural, en las que se reconoce la realidad del Estado social y democrático de derecho ${ }^{22}$. Desde este punto de vista, puede aceptarse que constituyen verdaderas misiones de servicio público que resultan imperativas para los poderes públicos; lo que a su vez permite una identificación de esta actividad pública con la libertad de configuración que reconocían los artículos 16 y 86.2 del Tratado de Maastricht (1992) a los Estados, para modular la libre competencia y oponerse a la privatización de los servicios económicos de interés general, cuando resulte necesario para salvaguardar las tareas o misiones específicas que le estuvieran encomendadas, que no pueden ser otras que la salvaguardia de los principios del Estado social y democrático de Derecho.

En el Derecho español, la lista de misiones específicas del poder público figura directamente en la CE, y ahora en los reformados Estatutos de Autonomía (Cataluña y Andalucía, fundamentalmente), que incorporan su propia «Carta» de derechos sociales, medio-ambientales y culturales, a modo de actualización de los principios rectores de la política económico y social establecidos en la $\mathrm{CE}$, a los que vienen a complementar. La CE impone y obliga a desplegar una actividad política concreta, pero no establece una obligación de resultado ni las fórmulas concretas de actuación para alcanzarlo ${ }^{23}$. Las formas concretas de prestación quedan en la CE a disposición de las distintas opciones políticas que indefectiblemente se inclinarán, según su signo, por una sector público amplio o estricto, y por un mayor o menor reconocimiento directo de derechos sociales y culturales a cargo de las Administraciones públicas, que tienen que soportar la carga de la prestación de los servicios públicos asistenciales ${ }^{24}$.

\subsection{Las obligaciones económicas del poder público en la CE}

La Constitución española de 1978 reconoce el ejercicio de la iniciativa pública en materia económica, incluida la posibilidad de reservar en monopolio

\footnotetext{
22 F. GARRIDO FALLA: «El concepto de servicio público en el Derecho Español» RAP, núm. 135, septiembre-diciembre de 1994 (CEPC), Madrid.

23 Alejandro HUERGO LORA: «La libertad de empresa y las técnicas de colaboración de colaboración preferente de las Administraciones Públicas con empresas públicas.» RAP, núm. 154, enero-abril, de 2001, págs. 169-171, (CEPC) Madrid.

24 La constitucionalización de los fines del estado social y democrático es una publicatio reforzada de esas actividades para facilitar el acceso universal y generalizado a una amplia gama de prestaciones públicas. Y ello, es de notar, para todos los ciudadanos, en situaciones de igualdad y con una permanente demanda sobre su calidad. Fundamentan el axioma del nuestro TC sobre el imposible retroceso en las demandas sociales.
} 
los servicios esenciales, pero atribuye el papel económico preponderante al mercado, como lo evidencia el reconocimiento de la libertad de empresa en la Sección 2. " "De los derechos y deberes de los ciudadanos», del capítulo II del Título I CE: «se reconoce la libertad de empresa en el marco de la economía de mercado. Los poderes públicos garantizan y protegen su ejercicio y la defensa de la productividad, de acuerdo con las exigencias de la economía general y, en su caso, de la planificación». El artículo $38 \mathrm{CE}$ garantiza el principio de libertad de empresa en el marco de una economía de mercado, configurándolo como verdadero derecho fundamental distinto de la propiedad privada y la herencia, pero dotado de la misma protección jurídica, de acuerdo con las leyes que lo desarrollen que no podrán desconocer su contenido esencial (artículo 53.1CE); y refiriendo el posible papel de los poderes públicos en la delimitación de este derecho a la defensa de la productividad, de acuerdo con las exigencias de la economía; quedando la planificación como una mera posibilidad excepcional, que no debe confundirse con las competencias reservadas al Estado por las cláusulas 11 a 14 del artículo 149.1.CE para la dirección de la política económica, fiscal y monetaria ${ }^{25}$.

No pueden aceptarse aquellas primeras opiniones doctrinales que se pronunciaban por un sistema económico constitucional neutral BASSOLS COMA, pues confundían las distintas posibilidades de administrar y dirigir la política económica con el reconocimiento explícito de la libertad de empresa. ${ }^{26}$ Tesis $^{2}$ que tuvieron refrendo constitucional en la S 36/1981, de 12 de noviembre, que identificaba tres posibles modelos económicos en el artículo 38 de la CE: una economía liberal, que reduce el papel del Estado a definir el orden jurídico; una economía social, en que el Estado garantiza la competencia empresarial y el funcionamiento del mercado, y está comprometido en el crecimiento económico y en el desarrollo de una política activa en la mejora de las condiciones de vida de los ciudadanos; y una economía dirigida (o controlada): el Estado tiene que corregir al mercado, que las políticas económicas aplicadas por los sucesivos gobiernos han desmentido. La CE establece el principio económico de libertad de empresa en el ámbito de una economía social y de mercado, que impone unas responsabilidades de servicio público, crecimiento y empleo a todos los poderes públicos, con independencia de su opción política.

El segundo título de intervención pública en la actividad económica figura en el artículo $131 \mathrm{CE}$ : «El Estado, mediante Ley, podrá planificar la actividad económica general para atender a las necesidades colectivas, equilibrar y armonizar el desarrollo regional y sectorial y estimular el crecimiento de la renta y de la

\footnotetext{
25 La CE 1978 se inclina por las tesis defendidas en la década de 1950 por VON MISES, HAYEK y ROBBINS a favor del mercado y en contra de la planificación - como principios de la actividad económica - en la larga contienda ideológica entre mercado y plan para dirigir la producción y la distribución de bienes y servicios, la CE se inclina por el mercado. La planificación queda enmarcada en una economía de mercado y para supuestos de verdadera excepción.
}

26 Bassols Coma. M.: «Constitución y sistema económico», Tecnos, Madrid, 1985 
riqueza y su más justa distribución», más que imponer o autorizar una economía planificada y centralizada, al referir la planificación a la atención de necesidades colectivas, la identifica con materias de servicio público y con situaciones de crisis económica de extrema gravedad, - como se ha puesto de manifiesto en las medidas excepcionales adoptadas por el Gobierno de España para superar la crisis bancaria y afrontar la crisis económica más profunda desde el célebre crash de la bolsa de Nueva York de 1929, que ha colocado la economía de los EEUU y de todo los países de la Unión Europea en recesión económica- ${ }^{27}$. En definitiva, la Constitución de 1978 autoriza la participación directa del Estado en economía (actividad empresarial) sujeta a libre competencia. Sólo cuando lo reclame el interés general, se podrán reservar por Ley recursos y servicios esenciales: el servicio público sólo puede identificarse con un servicio esencial. La Ley ordinaria es el título necesario para establecer y reservar al sector público los servicios públicos económicos que requiera el cumplimiento de las misiones establecidas en la CE. La participación o la iniciativa pública, en materia económica, no se identifica con la prestación de servicios públicos y no conlleva, en ningún caso, previa reserva o intervención de sectores económicos ${ }^{28}$; $\sin$ embargo, esta libertad quedará condicionada por la propia viabilidad de tales empresas o por situaciones de crisis económica. La década de 1980 estará marcada por la crisis económica y la imposibilidad de mantener en manos públicas los sectores económicos asumidos por el sector público español, acuciados por problemas de rentabilidad se verán obligados a frenar a la expansión del sector público económico, abrir al accionariado privado todos los sectores y asumir el coste del saneamiento de tales empresas; para terminar con la liquidación de empresas públicas inviables y evitar, incluso con el cierre, la nacionalización de las pérdidas ${ }^{29}$.

\subsection{Los servicios mínimos y las actividades o servicios esenciales en la Ley de Bases del Régimen Local}

La actividad económica y de prestación de los Entes Locales se dibuja en la Ley 7/85, de Bases de Régimen Local (LBRL), a imagen y semejanza de la CE, tienen reconocida plena capacidad para realizar todas aquellas actuaciones que afecten a la comunidad vecinal que representan (art. 25.1 LBRL), y están obligados a prestar a sus ciudadanos los servicios esenciales para la vida comunitaria del art. 26 LRBRL; en aplicación de los artículos 128 y 131 CE. La LBRL les reconoce la posibilidad de reservar en monopolio (municipalización) el lis-

27 RDL 5/2008, de 3 de octubre, por el que se crea un fondo para la adquisición de activos financieros; RDL 7/2007, de medidas urgentes financieras, en relación con el Plan de acción conjunta de la UE; y RDL 9/2008, por el que crea un Fondo Estatal de Inversión Local, y un Fondo especial del Estado para dinamizar la economía.

28 Julia ORTEGA BERNARDO «Competencias, servicios públicos y actividad económica de los municipios» RAP. Núm. 169, págs. 76-79, enero-abril 2006 (CEPC) Madrid.

29 J.F. VILlar RoJAS «Privatizaciones de servicios públicos» Madrid 1993. 
tado de servicios del artículo $86.3^{30}$, que se limita a trasladar a la Administración Local las previsiones constitucionales citadas en materia de reserva a favor del sector público; al mismo tiempo que reconoce en sus números 1 y 2 la plena libertad para el ejercicio de actividades económicas en régimen de libre competencia, y una libertad casi absoluta en materia de elección del modo de gestión, salvo que implique ejercicio de autoridad ${ }^{31}$.

La prestación en monopolio solo requiere acuerdo plenario y ratificación de la Comunidad Autónoma. El ejercicio de actividades económicas requiere tramitar un expediente que acredite su conveniencia acierto y oportunidad ${ }^{32}$; sin embargo la prestación de los servicios obligatorios no exige la reserva en monopolio ni existe identificación entre unos y otros; además, la prestación en monopolio no impone una gestión directa ni mucho menos un organismo público de gestión; por el contrario, la gestión por sociedad privada goza de general aceptación. Lo que dificulta la distinción entre servicio público y actividad económica ${ }^{33}$.

\section{DISTINCIÓN ENTRE SERVICIO PÚBLICO Y ACTIVIDAD ECONÓMICA DE LOS ENTES LOCALES}

La diferencia esencial entre servicios públicos y actividades económicas de los Entes Locales, habida cuenta de la libertad de formas de prestación que

30 J. M. DíAz LeMA (1994). De ello se deriva que la declaración de reserva establecida por el artículo 86.3 LRBRL no tiene un efecto jurídico inmediato, sino que implica un proceso escalonado en dos momentos sucesivos, que requieren implantar efectivamente la reserva o monopolio local, siempre que así lo deseen y cuenten con la autorización de la respectiva Comunidad Autónoma. En contra R. GómEz-FERRER MorANT, «La reserva al sector público de recursos o servicios esenciales», en Estudios sobre la Constitución española. Homenaje al Profesor Eduardo García de Enterría, V, Civitas, Madrid, 1991, pág. 3281, quien considera la reserva efectuada por la LRBRL «inmediatamente efectiva» Por su parte, S. MARTÍN-RETORTILLO BAQUER, Derecho Administrativo Económico, vol. I, La Ley, Madrid, 1988, pág. 318, si bien entiende que «las posibilidades que contempla el art. 86.3 se enuncian como hipótesis establecidas genéricamente, remitiéndose su concreción, es decir, la específica actualización de la reserva a dos acuerdos administrativos: el del Pleno de la Corporación y el del órgano de Gobierno de la Comunidad Autónoma», considera que tal previsión genérica resulta discutible toda vez que, a su juicio, la puesta en práctica de la reserva debería ser, conforme a la Constitución, obra directa de la ley. En el mismo sentido, F SOSA WAGNER, La gestión de los servicios públicos locales, 3.a) Ed. Civitas, Madrid, 1997, págs. 41 y ss. se refiere a la reserva como mera «legitimación» del sector público para asumir la gestión empresarial del recurso o servicio sustrayéndolo al régimen de libre empresa y no como una asunción directa, lo que comporta que sea posible la existencia de servicios sobre los cuales haya recaído declaración de reserva y que sean gestionados en régimen de libre concurrencia.

31 F. VILlaR RoJAS, «Los servicios esenciales reservados a las entidades locales», en Introducción a los Servicios Locales. Tipos de prestación y modalidades de gestión (Din J. M. DE LA CUÉTARA MARTínEZ), MAP, Madrid, 1991, pág. 184

32 STC 240/2006, también los configura como canon de constitucionalidad de la Ley autonómica.

33 La Ley 7/1999, de Administración Local de Aragón, parece identificar el ejercicio de actividades económicas por los entes locales con la efectividad de la reserva hecha a su favor por el arto 86 LRBRL, Y admite que los servicios reservados se presten en régimen de libre concurrencia o de monopolio (art. 205). El Texto Re- fundido de la Ley Municipal y de Régimen Local de Cataluña (Decreto legislativo 2/2003, de 28 de abril) distingue dentro de las actividades económicas de los entes locales, aquellas que tienen por objeto prestar un servicio público esencial reservado por la ley a los entes locales (arto 244), pudiendo prestarse en régimen de libre concurrencia o de monopolio (art. 245). 
autoriza el artículo 85 de la Ley 7/85, salvo la excepción del ejercicio de autoridad, no está en la forma pública o privada de organizar y prestar el servicio o la empresa; en principio, los servicios públicos locales en sentido estricto son los así declarados por Ley: los de prestación obligatoria y los reservados, artículos 26 y 86.3 de la LBRL ${ }^{34}$; por el contrario, la iniciativa publica en materia económica no se circunscribe a un listado de materias o actividades concretas, - salvo el respeto y la sujeción al principio de libertad de empresa del artículo $38 \mathrm{CE}$, que impone un límite efectivo al ejercicio de la iniciativa económica de los entes públicos, al exigir una actuación sin privilegios ni ayudas públicas-, sólo está condicionada por el interés público.

\subsection{Criterios de distinción}

Lo genuino del servicio público está en tratarse de una prestación pública garantizada de forma regular y continua, a un precio asequible, y que supone un régimen exorbitante ${ }^{35}$. Se trata de prestaciones públicas declaradas obligatorias por Ley y presididas por las notas de regularidad, universalidad e igualdad, y asequibiliad que se organizan al margen del mercado, y que tienen por finalidad a satisfacer una necesidad esencial. El servicio público implica un régimen excepcional, aunque se preste por sociedad privada, su mera existencia implica la existencia de ayudas públicas que de hecho impiden la prestación por el sector privado. La distinción esencial entre servicios públicos y actividades económicas de los entes locales está en el régimen de atribución competencial y en el sometimiento al mercado y las reglas de la competencia y de la contratación pública, o en la posibilidad de excluirlas por ejercicio de la reserva pública del servicio o de la actividad para su ejercicio o prestación directa, a través de medio propio; o indirecta, por concesión, pero siempre con exclusión del mercado, aunque no existe una distinción legal expresa.

Esta distinción existe en otros Estados europeos, el Derecho alemán distingue doctrinalmente entre actividad no económica (nicht wirtschaftliche Betatigung) y actividad económica (wirts-chaftlichte Betatigung); la actividad no económica presupone la existencia de una competencia administrativa - de acuerdo con su régimen de atribución competencial a favor del municipio - y

\footnotetext{
34 En nuestro ordenamiento jurídico la declaración legal de una actividad como servicio público local significa reconocer la competencia de la Corporación local y, en su caso, imponerle la realización de dicha actividad (art. 26 LRBRL), de manera que la misma se ejercerá, prima facie, en régimen de concurrencia con los particulares, salvo que haya sido, en la misma ley de atribución competencial o posteriormente en otro texto legal, reservada a la Corporación local en cumplimiento de la reserva de ley exigida por el artículo 128.2.

35 STS de 16 de mayo de 1997, que relaciona la prestación de los servicios públicos locales de carácter obligatorio con el derecho reconocido en la ley — art. 18.1.g) LRBRL - de todo vecino a exigir su efectiva ejecución. La formulación de este artículo 18.1.g) LRBRL como un derecho subjetivo de todo vecino de exigir la prestación y, en su caso, el establecimiento del correspondiente servicio público permitió que en el ámbito local pudiera impugnarse la inactividad de la Administración, lo que, como es sabido, no fue posible con carácter general frente a cualquier Administración hasta Ja entrada en vigor de la Ley 29/1998, de 13 de julio, reguladora de Ja jurisdicción contencioso-administrativa (arts. 25.2 y 29).
} 
coincide generalmente con el ejercicio de la misma en el ámbito de los servicios de asistencia vital (Daseinvorsorge), y sólo está condicionada a razones de interés público, a la capacidad de gestión del ente local, y a dirigirse a la satisfacción de una necesidad general, que no se pueda satisfacer de otra forma.

En nuestro Derecho, la distinción está en similares consideraciones, el servicio público se configura como en la $\mathrm{CE}$ como un servicio esencial, que requiere reconocimiento y declaración legal formal — «publicatio»-, quedando a cargo de las distintas Administraciones, de acuerdo con el reparto constitucional y legal de competencias entre los entes territoriales dotados de autonomía - las Comunidades Autónomas, según las competencias efectivamente asumidas en sus Estatutos, y los Entes Locales, de acuerdo con los criterios de atribución fijados en la ley-, establecer los sistemas de prestación y los concretos modos de gestión. Lo que ha generado una discusión doctrinal no cerrada sobre la necesidad o no de tramitar expediente para determinar el modo de gestión del servicio público y, en su caso, aprobar formalmente su reserva en monopolio, o si por el contrario, el expediente que se regula en los artículos 97 y siguientes del DL 781/86, sólo resulta exigible para el ejercicio de actividades económicas $^{36}$, y sobre si existe alguna traba o condicionamiento sobre la reconocida libertad de elección del modo de gestión ${ }^{37}$. La jurisprudencia del Tribunal Supremo - STS de 23 de mayo de 1997, relativa a la gestión del servicio de aguas por órgano especial sin personalidad jurídica - y una gran parte de la doctrina entiende que se trata de un requisito que sólo es exigible para el ejercicio de la actividad económica. Tesis que sólo se han resentido cuando se opta por una gestión privada de un servicio público ${ }^{38}$, pero que no cuenta con el imprescindible respaldo normativo, antes al contrario, la Ley 57/2003, de Medidas de Modernización del Gobierno Local, mantiene el sistema de libertad de formas de prestación que figuraba en la redacción original del art. 85 de la Ley 7/85, sin que la reserva en monopolio imponga, como pudiera parecer conveniente, una forma especial propia de la teoría del servicio público, aunque en todo caso, se requiere acuerdo del Pleno sobre el establecimiento efectivo en régimen de monopolio o de libre concurrencia.

\footnotetext{
36 J. DíAz LEMA y T. QuinTANA LÓPEZ, IMS «Mancomunidades en nuestro Derecho local», 1990, pág. 54. Entienden, por el contrario, que es necesario dicho expediente en todas las iniciativas municipales con contenido económico, sean o no servicios públicos, F. LLISET BORREL (1990: 26); F. J. FERNÁNDEZ GONZÁLEZ (1995: 57); J. F. AlenZA GARCíA (1997: 535); S. GonZÁLEZ-VARAS, «Levantamiento del velo y Derecho administrativo privado en el ámbito de la Administración local», REALA, núms. 274-275, 1997, pág. 364.

37 Valentín ESTRADA MERINO «La elección de las formas de prestación de los servicios públicos locales». Op. cit. 13.

38 STS de 1 de febrero de 2002 entiende que la prestación de un servicio público por sociedad mercantil en gestión directa es mas una intervención local en la economía bajo formas jurídico-privadas, que la prestación de un servicio y por lo tanto esa elección debe motivarse, en la medida que puede suponer restricciones o, al menos, afectar a la libertad de empresa y de mercado, resulta acertado. Además, es similar al que se utiliza en el Derecho local alemán, en el que se exige la formalización de un expediente que sirva de fundamento a la decisión municipal cuando se opta por utilizar formas jurídico-privadas en la gestión de los servicios públicos.
} 
El ejercicio de la iniciativa pública en materia económica local sólo requiere la existencia de un interés general (artículos 103.1 CE y 25 LRBRL), que tiene que aprobar el Pleno del Ayuntamiento apreciando la conveniencia y oportunidad de la medida ${ }^{39}$. Sin que resulte limitada, como en materia de servicios públicos, por la necesidad de una previa declaración legal de las actividades económicas susceptibles de asumirse por la Administración ${ }^{40}$, que aquí se traduce en la necesidad de tramitar un expediente que acredite la conveniencia y necesidad de una intervención municipal en la actividad económica, por aplicación del art. 103.1 CE, y por resultar obligado prever los efectos económicos y sociales de la intervención pública en el derecho a la libertad de empresa que garantiza el art. $38 \mathrm{CE}^{41}$, que constituye un verdadero contrapeso al derecho de iniciativa pública, en cuanto se configura como derecho subjetivo con acción ante los tribunales ${ }^{42}$.

La cuestión central del sistema es la libre determinación por el Estado y por las CCAA, según las reglas de distribución legal de competencias, de las misiones de servicio público local, que autorizan el establecimiento y prestación de servicios públicos locales, que pueden imponerse coactivamente y financiarse al margen de las reglas del mercado ${ }^{43}$.

\subsection{Los problemas de la teoría del servicio público como prestación en monopolio}

El sistema de la Ley 7/85 sufrirá, en la década de los años 90 del pasado siglo, el embate de las Directivas comunitarias de liberalización de los servicios en red, que supuso una verdadera revolución política sobre el papel de la iniciativa o libertad de intervención de los Estados en materia de servicios de interés general. La doctrina española, aunque le ha prestado la debida atención a unos cambios que afectan directamente a la presencia del Estado en la gestión de servicios económicos ${ }^{44}$, no se ha manifestado sobre el alcance de la liberalización en rela-

39 T. DE LA CUADRA-SALCEDO (1999: 54-55) dentro de un margen muy amplio de discrecionalidad.

40 Resulta de aplicación el artículo 25.1 LBRL, que al igual que en Alemania mantiene el principio de universalidad de la competencia municipal, lo que significa que el municipio puede ejercer todos los asuntos de la comunidad local sin necesidad de un título especial.

41 En este sentido ex artículo 97 TRRL deben valorarse los riesgos, los costes, los gastos de mantenimiento y, también, los gastos financieros, y los efectos de la intervención para el conjunto de la actividad económica.

42 E. ARANA GARCÍA entiende que este expediente del artículo 97 del Texto Refundido viene a ser una aplicación local de la necesidad de motivación de toda actividad discrecional (art. 54.1.f) de la LRJPA) de la Administración, y que no supone una aplicación del principio de subsidiariedad».

43 F. GARRIDO FALlA: «El concepto de servicio público en el Derecho Español». Op. cit. n. ${ }^{\circ} 22$. Alejandro HUERGO LORA: "La libertad de empresa y las técnicas de colaboración de colaboración preferente de las Administraciones Públicas con empresas públicas. Op. cit. n . 22, págs. 169-171.

44 Pablo SALVAdOR CODERCH, «Del Servicio Público al servicio a la comunidad» RAP, núm. 136, eneroabril 1995 (CEPC) Madrid; Francisco Sosa WAGNER, y Mercedes FuERTES LÓPEZ, « ¿Pueden los contratos 
ción con las facultades y competencias del Estado para la intervención y reserva en monopolio de sectores económicos esenciales, que autorizan los artículos 128.2 y 131 de la CE, cuando no puede negarse que imponen una interpretación restrictiva del interés general que excluye de la posibilidad de nacionalizar o socializar los servicios liberalizados por el Derecho comunitario ${ }^{45}$.

La liberación de los servicios de interés general en el ámbito de la UE, por un lado impone la venta de los monopolios comerciales en los sectores liberalizados, por otro genera incertidumbre en cuanto a la posibilidad de contratar directamente con el resto de las empresas de gestión de servicios (medio propio), que perderían así toda posibilidad de subsistir. Las dudas y vacilaciones habrán de esperar a la más reciente doctrina del TJCE para despejar las incógnitas sobre la viabilidad de todo tipo de servicios de interés económico general que siguen en manos de las Administraciones Públicas ${ }^{46}$. Este proceso creciente e imparable de liberalización de los servicios públicos y de pleno sometimiento al mercado, se corta drásticamente, a medida que la crisis financiera desatada en el verano de 2007 en los EE.UU., con el escándalo de las «subprime», se extiende a todos los Estado y a todos los sectores económicos generándose una crisis mundial de consecuencias todavía imprevisibles en el pasado 2008, que obliga a intervenir masivamente a la Reserva Federal y a al BCE, primero para rescatar bancos en crisis, inmediatamente, en el otoño de 2008, para garantizar fondos y depósitos, y ahora, para subvencionar directamente los sectores en crisis, cuando no para tomar directamente posiciones en el accionariado (UK). Las tesis liberalizadoras quedan para una nueva ocasión favorable, ahora a nadie se le ocurre poner en entredicho el ámbito de los servicios de interés económico general ni la iniciativa pública en materia económica, que ya no se limita a establecer unas reglas que permitan funcionar al mercado. El sistema de «publicatio» y de prestación en monopolio, ya no está en riesgo por contradecir los principios de libertad de empresa y de establecimiento ${ }^{47}$. La

\footnotetext{
quedar en casa? (la polémica europea sobre la contratación in house)» Premio La ley 2007.

45 La cesión de soberanía que supone el TUE implica aquí una evidente restricción de los poderes del Estado.

46 Sentencia del Tribunal de Justicia de Luxemburgo c-295/05, de 19 de abril de 2007, 55 «En cualquier caso, es preciso recordar que, según jurisprudencia reiterada del Tribunal de Justicia, de conformidad con las Directivas relativas a la adjudicación de contratos públicos, la licitación no es obligatoria, aunque el contratante sea una persona jurídicamente distinta del poder adjudicador, cuando se cumplan dos requisitos. Por una parte, la autoridad pública que es poder adjudicador debe ejercer sobre la persona distinta de que se trate un control análogo al que ejerce sobre sus propios servicios y, por otra parte, dicha persona debe realizar la parte esencial de su actividad con el ente o entes públicos que la controlan (véanse las sentencias de 18 de noviembre de 1999 [TJCE 1999, 270], Teckal, C-107/98, Rec. p. I-8121, apartado 50; de 11 de enero de 2005 [TJCE 2005, 1], Stadt Halle y RPL Lochau, C-26/03, Rec. p. I-1, apartado 49; de 13 de enero de 2005 [TJCE 2005, 10], Comisión/España, C-84/03, Rec. p. I-139, apartado 38; de 10 de noviembre de 2005 [TJCE 2005, 332], Comisión/Austria, C-29/04, Rec. p. I-9705, apartado 34, y de 11 de mayo de 2006 [TJCE 2006, 139], Carbotermo y Consorzio Alisei, C-340/04, Rec. p. I-4137.»

47 J. ORTEGA BERNARDO «Competencias, servicios públicos y actividad económica de los municipios». Op. cit., núm. 28.
} 
severidad de crisis económica mundial ha terminado con la pretensión de unificar bajo el principio de la competencia toda la actividad económica del sector público, y ha demostrado que no se puede tener una confianza absoluta en el mercado; con independencia de las ideologías políticas, la presencia y el control de la Administración es necesaria e irrenunciable en la actividad financiera, e imprescindible en la promoción económica, la educación y la investigación.

En este sentido, la calificación de una actividad como servicio público sigue siendo absolutamente decisiva para mantener la excepción del sometimiento al mercado en materia de financiación y de contratación; lo que permite mantener la prestación directa por «medio propio» de todo tipo de servicios de interés general, con justificación en la misión específica a ellos confiada, expresión que se ha mantenido en el TJCE desde su redacción original, a lo largo de todas las versiones y modificaciones, hasta su nueva definición en el Tratado de Lisboa. Y de ahí la necesidad de la declaración o reserva, sin la que no pueden mantenerse los servicios públicos, al quedar sometida toda la actividad pública a la regla de la competencia ${ }^{48}$.

\section{LA TEORÍA DEL SERVICIO PÚBLICO EN EL DERECHO COMUNITARIO: DEL TRATADO DE ROMA AL TRATADO DE MAASTRICHT}

El Tratado de la Comunidad Económica Europea, de 25 de marzo de 1957, establece las bases de un mercado único presidido por los grandes principios de Derecho Comunitario: libertad de circulación personal y no discriminación, libertad de prestación de servicios, el derecho de libre establecimiento, y las normas en materia de competencia y prohibición de ayudas estatales, que inciden de forma directa e inmediata sobre todo tipo de actividades económicas públicas o privadas. Los servicios públicos sólo se mencionaban en el art. 77 del $\mathrm{TCCE}^{49}$, en materia de transportes. Se trataba de una omisión consciente para evitar los efectos negativos de un concepto muy desdibujado de servicio público. Los redactores de los Tratados temían los efectos de la falta de operatividad de un concepto de servicio público con múltiples acepciones, que muy poco podía ayudar a la consecución de un mercado sin fronteras, y a extender la libre competencia en la mayoría de los sectores posibles con independencia de su titularidad; sin que tampoco tuviera utilidad para delimitar los sectores

\footnotetext{
48 STS de 10 de octubre de 1989 (Ar. 7352), sobre la iniciativa económica del Ayuntamiento de Barcelona-, no puede en ningún caso restringir el juego de la libre competencia del mercado.

49 Tomás Ramón FERnÁndeZ RodRíGUEZ «Del Servicio Público a la liberalización, desde 1950 hasta hoy» RAP, op. cit. 3 esta ausencia porque el concepto no es general, sino privativo de algunos Estados miembros, que han canalizado a lo largo de su historia preferentemente (aunque no exclusivamente, como ya hemos visto) por la vía de la publicatio formal de algunas actividades su respuesta a un problema que sí es general y común a todos ellos, cubrir la distancia existente entre el espacio vital dominado y el espacio vital efectivo, y que los demás han salvado por la vía alternativa de la regulación de las actividades en cuestión.
} 
público y privado; por otro lado, tampoco se buscaba el enfrentamiento directo con el poder de los monopolios estatales ${ }^{50}$.

\subsection{Los servicios de interés económico general}

El problema de los límites del servicio público y de la actividad económica de los poderes públicos al margen del mercado, y las modulaciones al principio de la libre competencia que tales prestaciones pudieran justificar quedaban anunciadas en el artículo 90.2 del Tratado de la Comunidad Europea (86.2 versión Maastricht), "las empresas encargadas de la gestión de servicios de interés económico general o que tengan el carácter de monopolio fiscal quedarán sometidas a las normas del presente Tratado, en especial a las normas sobre competencia, en la medida en que la aplicación de dichas normas no impida, de hecho o de derecho, el cumplimiento de la misión específica a ellas confiada.» El Derecho comunitario, para superar las diferencias entre los estados de corte francés y sistema de la «publicatio» formal de actividades de servicio público, y de los siguen la vía de la regulación de las obligaciones de servicio público, adopta sus propias formas y definiciones: la expresión «misión específica» y la de «servicios de interés económico general» engloba las distintas acepciones de la teoría del servicio público ${ }^{51}$, para establecer un concepto propio, cuya fuerza expansiva le permite afianzarse sobre el Derecho de los Estados.

Las menciones a los «servicios de interés general» figuraban en los artículos 16, 30, 46, 73 y apartado 2 del artículo 86 del TCEE para identificar las actividades económicas de interés general creadas por las autoridades públicas o a las que funcionan bajo su responsabilidad. El concepto se aplicaba también a las actividades económicas denominadas de prestación en red o servicios de redes: distribución de electricidad, gas y agua, correos y telecomunicaciones. El Tratado de Roma los configuró como «derechos especiales» o «exclusivos» en los artículos 31.1, y 86.2, que autorizan la existencia de derechos especiales o exclusivos (prestación en monopolio), en materia de prestación de servicios de interés económico general, siempre que así lo exija la misión específica a ellos confiada. Por el contrario, las Empresas Públicas, artículos 86 y 295, no tienen tratamiento especial en el Tratado y les resultan de aplicación todas las normas comunitarias sobre prohibición de toda discriminación por razón de nacionalidad y las reglas de competencia sin excepción. La vinculación evidente entre las autoridades pú-

\footnotetext{
50 Por el contrario, la libertad de circulación personal y el principio de no discriminación tienen un alcance general y resultan de obligada aplicación en todos los ámbitos, especialmente, en los denominados servicios de interés general no económicos, que se identifican con los denominados derechos sociales y asistenciales: acceso a la cultura y a la educación, a la sanidad y a los servicios sociales, de tal manera que se oponen a toda regla fiscal o administrativa que directa o indirectamente beneficie a los nacionales de los Estados sobre el resto de ciudadanos de la Unión.
}

51 Villar Ezcurra, «Derecho Administrativo Especial. Administración Pública y actividad de los particulares», Ed. Civitas, Madrid, 1999), 
blicas y empresas estatales y la realidad de distintos regímenes de ayudas obligaron a la Comisión a establecer una vigilancia especial, y a la aprobación de la Directiva 80/723, de 25 de junio, sobre transparencia de las relaciones financieras entre los Estados miembros y sus empresas públicas ${ }^{52}$.

La tensión entre los principios de libre mercado y el monopolio de los servicios de interés general se agudiza desde la entrada en vigor del Acta Única de 1986, que configuró un verdadero mercado único, añadiendo la libertad de movimientos de capitales y de personas. Sin embargo, su influencia fue nula en la LBRL, que diseñó un sistema de prestación de servicios públicos y actividades económicas locales, a imagen y semejanza de la $\mathrm{CE}$, sin remisión o referencia alguna a los principios del TCEE; regulando una reserva en monopolio en el artículo 86.3 con un ámbito más teórico que efectivo. Los efectos del Derecho comunitario se harán realidad en la década siguiente, coincidiendo con un cambio de Gobierno en España, y en plena ebullición del proceso liberalizador de las empresas públicas, y de la liberalización de los servicios en red, se aprobarán los Reales Decretos Leyes 5, 6 y 7 de 1996, de medidas liberalizadoras en materia de colegios profesionales, suelo, medidas fiscales, telecomunicaciones, actualización de balances, sistema energético y de reducción de la presión fiscal que, por primera vez, afectarán a los monopolios locales al eliminar la reserva de los servicios mortuorios y los de matadero. La regulación de los servicios locales afronta el primer embate de las políticas liberalizadoras perdiendo su monopolio legal en materia de servicios mortuorios y los de matadero, que hacía tiempo estaban en obsolescencia, al igual que los de distribución de gas y energía, que evidentemente chocaban con las Directivas liberalizadoras de los servicios de redes que aprobarán inmediatamente. Por curioso que parezca, la siguiente reforma de la Ley 7/85, por la Ley 57/2003, de Medidas para la Modernización del Gobierno Local, en materia de servicios locales, se limita a identificar la prestación de servicios con el ejercicio de competencias y a introducir las fórmulas estatales de la LOFAGE, pero no aparece referencia alguna al Derecho comunitario ni a los servicios de interés general, cuando la identificación entre servicios reservados y las a misiones de interés general del artículo 86.2 TCEE era manifiesta y la referencia resultaba obligada ${ }^{53}$.

\subsection{El concepto de servicio universal}

El concepto de servicio universal nace al socaire de las Directivas liberalizadoras de los servicios económicos de red (telecomunicaciones, electricidad,

\footnotetext{
52 El suministro regular de información y las reclamaciones para la devolución de ayudas contrarias a los Tratados se imponen definitivamente con la modificación de la Directiva en 1993.

53 Esto es definitivamente así, según la jurisprudencia comunitaria, como se expondrá a continuación en el texto. Aunque, por lo visto - lo pone de manifiesto M. CAMPOS SÁNCHEZ-BORDONA (2004: 75) -, existían en la Comisión Europea bastantes reticencias al respecto, era un tópico admitido por la Comisión que en el ámbito local, dada su menor importancia, no tenían la misma aplicación las normas comunitarias sobre competencia.
} 
servicios postales), para garantizar que tales servicios se presten a los consumidores con una calidad mínima igual en todo el territorio a un precio asequible, que asegure la regularidad y universalidad de la prestación ${ }^{54}$. Se trata de reconocer a todos los ciudadanos de la UE el derecho a acceder a ciertos servicios considerados esenciales y de imponer a las empresas la obligación de prestar un servicio mínimo en las condiciones especificadas, incluida una cobertura completa del territorio. Lo que supone un concepto material de servicio público, al incorporar la técnica anglosajona de las utilidades públicas. Como dice MUÑÓZ MACHADO, el servicio público pierde su carácter orgánico, para pasar a ser una noción material, que se refiere a actividades gestionadas en condiciones jurídicas exorbitantes del derecho común, tanto por las Administraciones públicas como por los particulares ${ }^{55}$.

Hasta el nuevo Tratado de Lisboa de 2007, el Derecho Comunitario originario no abordaba la cuestión de la competencia material sobre la regulación de estas condiciones operativas materiales de los servicios públicos que justificasen la excepción a la libertad de establecimiento, y libertad de mercado, quedando en manos de los Estados, a falta de legislación comunitaria específica (Directivas, normalmente), definir los requisitos relativos a la cobertura territorial, niveles de calidad y seguridad, derechos de los usuarios o la protección del medio ambiente, y establecer las correspondientes compensaciones sin perjuicio de los poderes de la Comisión ${ }^{56}$. En la aplicación de esta nueva técnica, la Administración se limita a ejercer potestades de regulación y control; se hablaba de una nueva función administrativa o función reguladora ${ }^{57}$, al servicio del movimiento privatizador de los servicios económicos de los Estados, en un

54 Directiva 2002/21/CE, del Parlamento Europeo y del Consejo, de 7 de marzo de 2002 (LCEur 2002, 1040), relativa a un marco regulador común de las redes y los servicios de comunicaciones electrónicas (Directiva marco), pero también por otras Directivas específicas, en concreto la Directiva 2002/20/CE (Directiva autorización); la Directiva 2002/22/CE (Directiva servicio universal); la Directiva 2002/19/CE) (Directiva acceso); y la Directiva 97/66/CE.

55 DE LA CUÉTARA y A. GONZÁLEZ SANFIEL, «Servicio universal y obligaciones de servicio público en la Ley del Sector eléctrico», «Economía Industrial», núm. 316, 1997.

56 Sobre el problema del rango de tales regulaciones, M. ${ }^{\mathrm{a}}$ Yolanda FERNÁNDEZ GARCíA «Las obligaciones económicas de los operadores de los servicios esenciales económicos en red», RAP, pág. 127-140, núm. 163, enero-abril, (CEPC), Madrid, 2004.

57 J.L. MARTíneZ LÓPEZ-MuÑIZ. «La regulación económica en España», en vol. Col. «El nuevo Servicio Publico», Marcial Pons, Madrid 1997, pág. 249. La legislación española ha recogido este concepto de servicio universal. Así la Ley del Sector Eléctrico proclama que abandona la noción de servicio público, tradicional en nuestro ordenamiento pese a su progresiva pérdida de trascendencia en la práctica, sustituyéndola por la expresa garantía del suministro a todos los consumidores usuarios demandantes del servicio dentro del territorio nacional. La Ley General de Telecomunicaciones se limita a decir que «las telecomunicaciones son servicios de interés general que se prestan en régimen de competencia». Del mismo modo, la Ley 2/1997, de 3 de abril, que suprimió los servicios funerarios de entre la lista de servicios que, según el art. 86.3 LRBRL, podían ser municipalizados, declara que los servicios funerarios son «servicios esenciales de interés general», a los que son aplicables los principios de universalidad, continuidad y accesibilidad, sujetando a los operadores en el sector a licencia municipal y a la regulación que el municipio establezca, pudiendo imponer prestaciones forzosas distribuidas por el Ayuntamiento entre las empresas funerarias que operen en el término municipal. 
movimiento identificado como «despublicatio»58; que implica la desaparición del servicio público, como fórmula de organización y gestión de determinados servicios esenciales económicos ${ }^{59}$.

\subsection{El Servicio de interés económico general en el Tratado de Maastricht}

Al mismo tiempo que se afianzaba la noción de «servicio universal», como técnica regulatoria de los servicios liberalizados, la Comisión Europea abría un proceso de discusión sobre el alcance y la viabilidad de los tradicionales servicios de interés económico general para reforzar su posición en el Derecho comunitario como excepción de la libre competencia. Se buscaba un concepto europeo de servicio de interés general que ayudase a deslindar los sectores público y privado de la economía y a la distribución de las competencias entres los Estados y la Unión ${ }^{60}$. El Tratado de Amsterdam asume en parte la Comunicación de la Comisión sobre los servicios de interés económico general y los incluye, por primera vez, como principio comunitario, artículo 16 (7 D): «Sin perjuicio de los artículos 73, 86 y 87, y a la vista del lugar que los servicios de interés económico general ocupan entre los valores comunes de la Unión, así como de su contribución a la cohesión social y territorial, la Comunidad y los Estados miembros, con arreglo a sus competencias respectivas y en el ámbito de aplicación del presente Tratado, velarán por que dichos servicios funcionen con arreglo a principios y condiciones que les permitan cumplir su cometido» ${ }^{61}$. El concepto de servicio de interés económico general se integra en la primera parte del Tratado, como principio estructural de la Comunidad, en cuanto representa los valores de solidaridad, que resultan imprescindibles para la promoción de la cohesión social y territorial. Tras el Tratado de Amsterdam, la Comisión adopta la Comunicación sobre los Servicios de Interés General en Europa, de 20 de septiembre de 2000, en un nuevo y renovado esfuerzo por definir los

\footnotetext{
58 Carlos CASSAGNE «Evolución de los principios aplicables a los servicios públicos y problemas actuales tras los procesos de privatización», RAP Núm. 157, Enero-abril de 2002 (CEPC), Madrid.

$59 \ll \ldots$ aquellas que se establecen de manera singularizada con la finalidad principal de garantizar la generalidad y continuidad del servicio correspondiente o el libre juego de la competencia, y que consisten en prestaciones activas o pasivas que los operadores no asumirían, o no harían en la misma medida ni en las mismas condiciones, si consideraran su propio interés comercial y financiero».

60 El primer intento de establecer un concepto homogéneo hay que verlo en la Comunicación de la Comisión sobre «los servicios de interés general en Europa», de 11 de septiembre de 1996, que aconseja un tratamiento general y común a todos los Estados, para establecer una verdadera política europea de los servicios públicos, se propone consagrar este concepto en el Tratado, coordinar los órganos nacionales de reglamentación y desarrollar redes europeas.

61 Declaración política solemne incorporada al Acta Final, refuerza su posición y explica la evolución posterior: «sus disposiciones se aplicarán con pleno respeto a la jurisprudencia del Tribunal de Justicia, entre otras cosas en lo que se refiere a los principios de igualdad de trato, calidad y continuidad de dichos servicios».
} 
respectivos ámbitos del servicio de interés económico general y las reglas de la competencia $^{62}$.

La misma idea se repite en el artículo 36 de la Carta de los Derechos Fundamentales de la Unión Europea, que figura como una declaración solemne de las instituciones comunitarias anexa al Tratado de Niza, de diciembre de 2000. «La Unión reconoce y respeta el acceso a los servicios de interés económico o general, tal como disponen las legislaciones y prácticas nacionales, de conformidad con el Tratado constitutivo de la Comunidad Europea, con el fin de promover la cohesión social y territorial de la Unión» ${ }^{63}$. Sin que el artículo 16 del Tratado de Niza modifique o añada alguna nota a la redacción del Tratado de Amsterdam $^{64}$. La inclusión en la Carta del derecho de acceso al «servicio universal» atribuye a los contenidos tradicionales del servicio público la primacía que corresponde al Derecho comunitario en el ámbito del Tratado, que desplaza la aplicación de la legislación nacional ${ }^{65}$, de acuerdo con los niveles de protección que reconocen los artículos 52.1 y 2, y 53 de la propia Carta.

\section{EL DEBATE SOBRE LA COMPETENCIA LEGISLATIVA DE LA UNIÓN EUROPEA EN MATERIA DE SERVICIOS DE INTERÉS ECONÓMICO GENERAL}

\subsection{Libro Verde de la Comisión Europea, de 21 de mayo de 2003, sobre los servicios de interés general}

La conciliación entre la primacía de las normas sobre competencia y libertad de movimiento de capitales y personas en la Unión con el mantenimiento de un sector público titular de empresas y de servicios de interés económico general, sin perjuicio del sector asistencial, exige una parte importante de las iniciativas políticas de la Comisión y del Parlamento, y genera los debates políticos más intensos entre los Estados y las instituciones de la Unión Europea en los 7 años que transcurren desde la aprobación del Tratado de Niza

\footnotetext{
62 Comunicaciones sobre los servicios de interés general [COM (1996) 443 y COM (2000) 580 - Diario Oficial C 281 de 26.9.1996 y Diario Oficial C 17 de 19.1.2001];

63 Los artículos 52 y 53 de la Carta establecen un nivel de protección equivalente al de los propios tratados, de acuerdo con el Convenio Europeo de Derechos Humanos, y del principio de legalidad.

64 «Sin perjuicio de los artículos 73, 86 y 87, y a la vista del lugar que los servicios de interés económico general ocupan entre los valores comunes de la Unión, así como de su papel en la promoción de la cohesión social y territorial, la Comunidad y los Estados miembros, con arreglo a sus competencias respectivas y en el ámbito de aplicación del presente Tratado, velarán por que dichos servicios actúen con arreglo a principios y condiciones que les permitan cumplir su cometido».

65 GONZÁLEZ CAMPOS y MuÑOZ MACHADO «Las competencias y el funcionamiento del TJCEE. Estudio analítico de los recursos». Tratado de Derecho comunitario. T. Y Madrid 1986. BACIGALUPO, M. «La Justicia Comunitaria. Estudio sistemático y textos normativos básicos», Marcial Pons, 1995 Madrid.
} 
hasta la suscripción del Tratado de Lisboa. En el informe de la Comisión sobre las ayudas estatales relacionadas con los servicios de interés económico general $^{66}$, se propone dar un paso más y entrar directamente en su definición para determinar el alcance de la libertad de configuración de los Estados miembros, el ámbito de aplicación de las normas comunitarias sobre ayudas estatales, las relaciones entre Estados y empresas encargadas de estos servicios (medio propio), y las modalidades de selección de las empresas encargadas de los servicios.

La importancia de la discusión política obliga a la Comisión Europea a entrar en el estudio del problema con la redacción de un Libro Verde ${ }^{67}$, que reconoce abiertamente el problema: «los servicios de interés general se encuentran en el eje del debate político. Afectan a la cuestión central del papel desempeñado por las autoridades públicas en una economía de mercado, a saber, por una parte, velar por el buen funcionamiento del mercado y el respeto de las reglas del juego por todos los protagonistas, y por otra, garantizar el interés general, en particular, la satisfacción de las necesidades esenciales de los ciudadanos y la conservación de los bienes públicos cuando el mercado no lo consigue» 68 .

La complejidad del concepto de servicio de interés económico general, que se confunde con las actividades y objetivos del poder, y que se organiza y presta, a través de una verdadera maraña de empresas y organismos públicos con diversos niveles de autogobierno y distribución territorial del poder en cada país, que a su vez admiten diversas formas de gestión y de colaboración público-privada, sin establecer una preferencia por las personificaciones de derecho público - única forma que se corresponde con el canon tradicional de servicio público, salvo cuando se trata de servicios directamente relacionados con el ejercicio de autoridad $-{ }^{69}$, obliga a ceder a la Comisión y abandonar sus intenciones de promover una Directiva específica sobre los servicios de interés económico general ${ }^{70}$. Se asume, por el momento, la imposibilidad de presentar una propuesta de Directiva marco sin renunciar por completo al debate sobre el alcance de una eventual acción comunitaria conforme al Tratado. En el mis-

\footnotetext{
66 COM (2002) 636 final del 27.11.2002 - no publicado en el Diario Oficial.

67 COM (2003) 270 final - Diario Oficial C 76 de 25.3.2004.

68 El TRATADO DE LISBOA asume expresamente la diferenciación.

69 Se mantiene en vigor la vieja distinción entre actos d autoridad y gestión (DUGUIT) que tiene presencia directa en el Reglamento de Servicios de las CCLL de 1955, y en el artículo 92.2 de la vigente Ley 7/85, de 2 de abril, de Bases del Régimen Local.

70 La Comisión se plantea la posibilidad y la conveniencia de establecer una normativa horizontal y general sobre el alcance de las competencias de los poderes públicos para garantizar el buen funcionamiento del mercado y salvaguardar el interés general, se plantea si la liberalización «controlada» de los servicios de redes puede extenderse al resto de los servicios económicos de interés general, a través del mecanismo o técnica del servicio universal, que garantiza el acceso a un servicio de calidad especificada, a un precio asequible, a todos los ciudadanos independientemente de su situación económica, social o geográfica.
} 
mo sentido, el Consejo solicitó un estudio de los aspectos básicos de los servicios de interés general ${ }^{71}$, para determinar los principios que podrían incluirse en una eventual Directiva marco y el valor añadido de un instrumento de esta índole ${ }^{72}$.

\subsection{La financiación de los servicios económicos de interés general}

En definitiva, para el Libro Verde resultaba imprescindible determinar la posible actuación de la Unión en el Derecho Comunitario originario, establecer una competencia compartida entre la Unión y los Estados, y fijar definitivamente un concepto comunitario de servicio de interés económico general que supere definitivamente los problemas del concepto de servicio público y las distintas acepciones de los Estados; A tal efecto, se propone codificar en el Derecho originario el concepto de servicio universal que establece los requisitos de interés general que garantizan que ciertos servicios se ponen a disposición de todos los consumidores y usuarios en todo el territorio de un Estado miembro con independencia de su situación geográfica con una misma calidad y, en función de las circunstancias nacionales, a un precio asequible ${ }^{73}$.

En cuanto a su financiación, es evidente que la mayoría de los servicios de interés económico general no se financian con el recurso exclusivo al mercado, siendo necesarios mecanismos específicos para asegurar el equilibrio financiero del Ente responsable de su prestación. Se utilizan todo tipo de técnicas: concesión de ayudas financieras directas a cargo del presupuesto del Ente Público (subvenciones); o indirectas (desgravaciones fiscales); concesión de derechos especiales o exclusivos (monopolio legal); la imposición de contribuciones de los participantes en el mercado (fondo de servicio universal); y el mecanismo de la equiparación de tarifas o tarifa única, aunque existan considerables diferencias en el coste del suministro del servicio. La financiación solidaria, (vía impuestos) se reserva, normalmente, para atender el coste de los servicios de interés general: seguridad social, enseñanza, sanidad, y servicios sociales. En

\footnotetext{
71 Propuestas que figuraban en el Informe al Consejo Europeo de Laeken titulado «Servicios de interés general» [COM (2001) 598 - no publicado en el Diario Oficial].

72 En el mismo sentido, se plantea la necesidad o conveniencia de establecer organismos de regulación a escala continental en los servicios de interés general que ayuden a establecer normativas generales; y la conveniencia de determinar los criterios que permitan distinguir cuando un servicio tiene naturaleza económica o asistencial.

73 Este concepto, acuñado específicamente para ciertas industrias de redes, reconoce a todos los ciudadanos el derecho a acceder a ciertos servicios considerados esenciales e impone a las industrias la obligación de prestar un servicio definido en condiciones especificadas, incluida una cobertura territorial completa. En un entorno de mercado liberalizado, una obligación de servicio universal garantiza que todos los ciudadanos tienen acceso al servicio a un precio asequible, y que se mantiene - y, en su caso, se mejora - su calidad. El concepto de servicio universal tiene carácter dinámico, lo que permite garantizar que los requisitos de interés general tienen en cuenta la evolución política, social, económica y tecnológica y, en su caso, se adaptan regularmente a las necesidades cambiantes de los ciudadanos.
} 
este contexto, la Comisión y el Consejo sólo contaban con los poderes y las obligaciones dimanantes del Pacto de Estabilidad de 1997, sin que tampoco existieran criterios legales que posibilitasen un examen real del grado de distorsión de la competencia que genera la concesión de ayudas, y menos del nivel o importancia del sacrificio de los intereses generales que puede generar su prohibición; por todo ello, resultó obligado abrir un debate sobre la posible atribución competencial a la Comunidad para definir las excepciones correspondientes a las misiones de servicio público, en materia de financiación de los servicios de interés económico general y abandonar las iniciativas legislativas en la materia $^{74}$.

\subsection{Comunicación de la Comisión Europea al Parlamento Europeo, al Consejo, al Comité Económico y Social y al Comité de las Regiones, de 12 de mayo de 2004: «Libro Blanco sobre los Servicios de Interés General»}

La Resolución del Parlamento Europeo, de 13 de enero de 2004, relativa al Libro Verde sobre los servicios de interés general, emplaza a la Comisión a dar respuesta a las múltiples consultas, expectativas y problemas puestos de manifiesto por el Libro Verde sobre el papel de la Unión Europea en la definición de los servicios de interés general, en relación con la libertad de establecimiento y con el juego de la libre competencia en la prestación de los servicios de interés general, obligan a la redacción de un nuevo Libro (Blanco $)^{75}$, que fije la posición de la Comisión y contribuya a dar una respuesta en el ámbito de la reforma de los Tratados $^{76}$.

En el nuevo Libro, se propone un reparto de las responsabilidades entre la Unión y los Estados miembros - y sus autoridades regionales y locales - en la definición, organización, financiación y control de los servicios de interés eco-

74 El debate iniciado por el Libro Verde despertó considerable interés y fue favorablemente acogido por muchos de los interesados. La Comisión recibió cerca de 300 contribuciones, procedentes de participantes muy diversos, incluidos muchos de los Estados miembros. Los servicios de la Comisión han preparado un Informe sobre la consulta pública, en el que se analizan las contribuciones remitidas y se aporta material de referencia para el presente Libro Blanco. En respuesta a la petición del Parlamento Europeo en su Resolución sobre el Libro Verde, de 14 de enero de 2004, la Comisión plasma en el Libro Blanco las conclusiones extraídas del debate. El Comité Económico y Social Europeo y el Comité de las Regiones han estudiado asimismo las cuestiones planteadas en el Libro Verde y emitido los correspondientes dictámenes. Dictamen relativo al Libro Verde sobre los servicios de interés general, CESE 1607/2003, 11.12.2003. Dictamen del Comité de las Regiones, de 20 de noviembre de 2003.

75 [COM (2004) 374 final - no publicada en el Diario Oficial].

76 Las diferentes posiciones de los Estados sobre la liberalización de los servicios económicos de interés general y, especialmente, sobre la necesidad de introducir el principio de libre competencia en materia de servicios sociales (educación, sanidad, atención a la infancia, juventud vejez, lucha contra la exclusión social), obliga a reconocer la manifiesta imposibilidad de aprobar una propuesta de directiva marco en la materia y sugiere que la Comisión vuelva a examinar la cuestión en una fase posterior. 
nómico general del art. 86.2 del TCEE77, que se asume directamente en el proyecto de Constitución Europea: «Sin perjuicio de los artículos III-55, III-56 y III-136, y a la vista del lugar que los servicios de interés económico general ocupan, como servicios a los que en la Unión todos conceden valor, así como de su papel en la promoción de la cohesión social y territorial de ésta, la Unión y sus Estados miembros, con arreglo a sus competencias respectivas y en el ámbito de aplicación de la Constitución, velarán por que dichos servicios actúen con arreglo a principios y condiciones, económicos y financieros en particular, que les permitan cumplir su cometido. Dichos principios y condiciones se definirán mediante leyes europeas.»Lo que proporcionaba definitivamente el necesario fundamento jurídico a la actuación de la Comunidad, con arreglo a las competencias de la Unión y en el ámbito de aplicación de la Constitución Europea.

Sin embargo, a pesar de la falta de normativa comunitaria, la discrecionalidad de los Estados para establecer funciones y misiones de servicio de interés económico general puede chocar con los principios de Derecho Comunitario, especialmente, cuando se aprueban los sistemas de financiación y las formas de organización y adjudicación de los contratos de gestión de dichos servicios. Los Estados miembros disponen de amplias facultades sobre la forma y la manera de financiarlos, con la única limitación de no falsear la competencia. A pesar de las Sentencias del Tribunal de Justicia sobre las condiciones en las que la compensación por servicios de interés económico general no constituye ayuda estatall $^{78}$, la Comisión entiende que subsiste la necesidad de una mayor seguridad

77 En consonancia con los principios enunciados en el artículo 16 del Tratado y en el artículo 36 de la Carta de Derechos Fundamentales, la Comisión se ha comprometido a tomar plenamente en consideración el papel específico de los servicios de interés general en las políticas y actividades que se enmarcan en su ámbito de competencia. Velará por que la Unión Europea siga aportando una contribución positiva al desarrollo de los servicios de interés general, que forman parte del modelo europeo, respetando, al mismo tiempo, la diversidad de tradiciones, estructuras y situaciones existentes en los Estados miembros. De acuerdo con los principios de mejora de la legislación1, la evaluación previa del impacto de las iniciativas importantes13 y la evaluación periódica de las políticas comunitarias pertinentes ayudarán a alcanzar tal objetivo.

78 Sentencia de 24 de julio de 2003 en el asunto C-280/00, Altmark Trans, núm.

89 En primer lugar, la empresa beneficiaria debe estar efectivamente encargada de la ejecución de obligaciones de servicio público y éstas deben estar claramente definidas.

90 En segundo lugar, los parámetros para el cálculo de la compensación deben establecerse previamente de forma objetiva y transparente.

91 Así, constituye una intervención financiera incluida en el concepto de ayuda de Estado en el sentido del artículo 92, apartado 1, del Tratado, la compensación por parte de un Estado miembro de las pérdidas sufridas por una empresa sin que se hayan establecido previamente los parámetros de tal compensación, cuando, «a posteriori», se comprueba que la explotación de determinados servicios en el marco de la ejecución de obligaciones de servicio público no ha sido económicamente viable.

92 En tercer lugar, la compensación no puede superar el nivel necesario para cubrir total o parcialmente los gastos ocasionados por la ejecución de las obligaciones de servicio público, teniendo en cuenta los ingresos correspondientes y un beneficio razonable por la ejecución de estas obligaciones.

93 En cuarto lugar, cuando la elección de la empresa encargada de ejecutar obligaciones de servicio público, en un caso concreto, no se haya realizado en el marco de un procedimiento de contratación pública que per- 
jurídica; por lo que propone adoptar las directivas y decisiones necesarias para promover la transparencia en las relaciones de los poderes públicos con sus empresas prestadoras de servicios; a tal efecto, se propone modificar la Directiva transparencia de $1980^{79}$, acompañando una Decisión que compatibilice con el mercado común la financiación pública de cuantía relativamente escasa a empresas a las que se ha encomendado la prestación de servicios económicos de interés general. Esta financiación quedaría exenta de la obligación de notificación previa, siempre que guarde proporción con el coste efectivo de los servicios y que no se superen determinados límites; y aprobar un nueva Directiva en materia de contratación armonizada (2004/18/CEE), que aclarase la cuestión del «medio propio» ${ }^{80}$.

Para superar estas dificultades, la Comisión se obligó a modificar, antes del mes de julio de 2005, la Directiva 80/723/CEE relativa a la transparencia de las relaciones financieras entre los Estados miembros y las empresas públicas, que será sustituida por la Directiva 2006/111/CE, de la Comisión, de fecha, 16-112006, que extiende las obligaciones de información y control a todo tipo de compensaciones y ayudas con fondos públicos a favor de toda clase de entidades y empresas públicas, cualquiera que sea su calificación jurídica con arreglo al artículo 87 del Tratado ${ }^{81}$. La Directiva no afectará a las relaciones financieras que no puedan afectar de forma apreciable al comercio entre los Estados miembros. Se excluyen los bancos centrales, las entidades de crédito públicas, y las empresas públicas cuyo volumen de negocios global neto anual en los dos ejercicios anuales anteriores al ejercicio en que se hayan puesto a disposición o utilizado los fondos mencionados en el artículo 1, apartado 1, haya sido inferior a 40 millones EUR ${ }^{82}$.

\footnotetext{
mita seleccionar al candidato capaz de prestar estos servicios originando el menor coste para la colectividad, el nivel de la compensación necesaria debe calcularse sobre la base de un análisis de los costes que una empresa media, bien gestionada y adecuadamente equipada en medios de transporte para poder satisfacer las exigencias de servicio público requeridas, habría soportado para ejecutar estas obligaciones, teniendo en cuenta los ingresos correspondientes y un beneficio razonable por la ejecución de estas obligaciones. Y STJCE, de 24 de noviembre de 2003, en los asuntos acumulados C-34/01 a 38/01.
}

79 Asimismo, la Comisión se propone modificar la Directiva 80/723/CEE relativa a la transparencia de las relaciones financieras entre los Estados Miembros y las empresas públicas. La modificación tiene por objeto precisar que la Directiva es aplicable a las compensaciones por servicio público, cualquiera que sea su calificación jurídica con arreglo al artículo 87 del Tratado. Ni la decisión de la Comisión ni el marco comunitario serán de aplicación en el sector del transporte.

80 STJCE, de 24 de julio de 2003 en el asunto C-280/00, Altmark Trans, Op. cit. 81, Y SSTJCEE Halle, de 11 de enero de 2005 (asunto c-26/03), y Mödling, de 10 de noviembre de 2005. asunto c-29/04.

81 El Estado español cumplió con su obligación de incorporación por Ley 4/2007, de 3 de abril, de transparencia de las relaciones financieras entre las Administraciones públicas y las empresas públicas, y de transparencia financiera de determinadas empresas.

82 Como demostración de la relación existente entre las normas sobre transparencia y sobre contratación pública, no será necesario aplicar esta Directiva a las empresas a las que se haya confiado la gestión de servicios de interés económico general a efectos del artículo 86, apartado 2, del Tratado, siempre que las compensaciones que reciban, cualquiera que sea la forma de la misma, se haya fijado por un período apropiado con arreglo a un procedimiento abierto, transparente y no discriminatorio. 


\section{EL SERVICIO DE INTERÉS GENERAL COMO PRINCIPIO ESENCIAL DE DERECHO COMUNITARIO: EL TRATADO DE LISBOA, DE 13 DE DICIEMBRE DE 2007}

El Tratado de Lisboa, de 13 de diciembre de 2007, sucederá al Tratado de Niza de $2001^{83}$, si tras la ratificación de todos los Estados miembros se supera definitivamente el resultado negativo del referéndum de la República de Irlanda, y la crisis abierta en el proceso de renovación de la Unión Europea, por el resultado fallido del Tratado Constitucional ${ }^{84}$. Lo que no ayuda a superar el estancamiento en el proceso de unidad europea en unos tiempos de crisis económica severa ${ }^{85}$; al mismo tiempo que se pierde la fuerza del impulso dado por Alemania para superar y abandonar el Tratado Constitucional e iniciar un procedimiento rápido de reforma, que salvara las cuestiones menos discutidas del Tratado Constitucional ${ }^{86}$. En cualquier caso, el Tratado de Lisboa peca de complejidad y extensión; junto con el texto de los dos nuevos Tratados (Unión Europea y Tratado de Funcionamiento), se adjuntan 11 Protocolos nuevos anexos al TUE, y al Tratado de Funcionamiento de la UE, que se unen a los 31 que subsisten; con el añadido de las tablas de correspondencias; 43 Declaraciones relativas a disposiciones de los Tratados; 7 Declaraciones relativas a Protocolos anexos, y 15 Declaraciones emitidas por diversos Estados miembros de las que la Conferencia ha tomado nota ${ }^{87}$.

En definitiva, el nuevo Proyecto de Tratado reproduce más del 95 por 100 del contenido del Tratado Constitucional, pero suprime todos los símbolos constitucionales (bandera e himno), para reconducir el proceso constitucional a un proceso de reforma de los Tratados que enlaza directamente con el anterior de Niza y man-

\footnotetext{
83 Reglas que, de acuerdo con lo dispuesto en el propio Tratado de Lisboa, van a mantener su aplicación en cuestiones sustanciales (como el cómputo de los votos del Consejo) hasta 2014.

84 El Proyecto se ratificó por 19 de los 27 Estados miembros de la Unión Europea, España entre ellos, sin llegar a entrar en vigor por el resultado negativo del referéndum francés, y del inmediato holandés, que abortaron el proceso en los siete Estados restantes, que ni siquiera lo sometieron a ratificación.
}

85 Manuel BALLBÉ, «El Futuro del Derecho Administrativo en la Globalización: Entre la americanización y la Europeización» RAP, núm. 174. Vol. especial «Homenaje al Profesor Ramón Parada Vázquez, septiembre-diciembre de 2007, Madrid, pág. 265: «mencionar las palabras constitución y federalismo en los sistemas multinivel es contraproducente, aunque sea nominal, los Estados se resisten a perder soberanía.» (E. Monnet).

86 La negociación ha sido inusitadamente acelerada - sin duda porque había un núcleo básico de materias consensuadas - y ha permitido concluirlo en cuatro meses y firmarlo dos meses después gracias a la exclusión los aspectos más polémicos y delicados del Tratado Constitucional y al establecimiento de cláusulas para exceptuar la aplicación del Tratado a aquellos Estados que más problemas podían tener en la ratificación (el Reino Unido y Polonia, sobre todo), de otra porque, salvo Irlanda, el procedimiento de ratificación va a ser parlamentario, excluyendo los riesgos que todo referéndum implica.

87 De este opaco bosque normativo no se va a proporcionar ninguna versión consolidada oficial durante el proceso de ratificación, seguramente para evitar facilitar su comparación con la Constitución Europea, por el temor de que resurjan dificultades políticas en algunos Estados miembros. Así pues, durante un tiempo serán inevitables los ejercicios de intertextualidad o el recurso a versiones no oficiales. 
tiene la tradicional estructura de textos y acuerdos separados; a los que cada vez en mayor número se unen los denominados Protocolos. En un intento de simplificación, los Tratados se denominan, respectivamente, Tratado de la Unión Europea (TUE) y Tratado sobre el Funcionamiento de la Unión Europea (TFUE); entre otras novedades, se asume por primera vez la denominación de Unión Europea a la que se atribuye personalidad jurídica y se superan los textos del TCCE y del TCECA y del EURATOM. Por otro lado, aunque formalmente no se incorpora la Carta de los Derechos Fundamentales, que no aparece en el texto de los Tratados, gracias a la insistencia de los representantes del Parlamento Europeo, su carácter vinculante se ha garantizado mediante la proclamación solemne por las tres instituciones políticas comunitarias - Parlamento Europeo, Consejo y Comisióntras su publicación en el Diario Oficial de la Unión Europea ${ }^{88}$. La Carta de los Derechos Fundamentales es el documento más importante de todo el proceso, puesto que es el único que se dirige a los ciudadanos, a los que confiere derechos exigibles ante los Tribunales. Lo que unido a la existencia de un Tribunal de Justicia, que interpreta e impone el Derecho comunitario sobre el particular de cada Estado, a través de la institución de la cuestión prejudicial, permite una mínima identificación ciudadana de las posibilidades de la «Justicia Comunitaria.»

En materia de servicios de interés económico general, el nuevo Tratado de Lisboa asume todas las propuestas y recomendaciones de los Libros Verde y Blanco. En el Protocolo de los Servicios de Interés Económico General se regulan las distintas categorías de servicios de interés general, distinguiendo entre servicios económicos de interés general y servicios de interés general no económicos, que no pueden resultar afectados por los Tratados ${ }^{89}$. Se cierra por el momento la discusión abierta por las Comunicaciones de la Comisión y los Libros Blanco y Verde sobre los servicios no económicos de interés general, que se sitúan extra muros de los Tratados. La Unión, que carece de competencia sobre los mismos: su organización, regulación y gestión es de plena discrecionalidad estatal; no obstante, la fuerza expansiva de los principios de los Tratados se manifestará en todo el ámbito de la selección del contratista; cuando se establezcan fórmulas indirectas de gestión de los servicios públicos asistenciales; en todos los supuestos de contratación armonizada; y en la aplicación de la doctrina del medio propio, cuando se presten por empresas, fundaciones o cualquier clase de entes creados ex profeso por la Administración titular de la competencia administrativa.

\footnotetext{
88 No aparece, por tanto, en el articulado de los tratados constitutivos, pero esa remisión le atribuye un rango jurídico similar al de estos. Conviene apuntar que los recelos hacia la Carta de algunos gobiernos como el inglés o el polaco provienen tanto de su posible utilización como base jurídica para incrementar la vis expansiva de las competencias comunitarias, cuanto de poder ser utilizados en materia de competencias privativas de los Estados. Por eso, el Tratado incorpora un Protocolo para acoger esas cautelas, que también se recogen en la propia Carta, al establecer que sus previsiones sólo se aplicarán a los Estados miembros cuando apliquen el Derecho de la Unión, y que no crean ni modifican las competencias de la Unión (art. 51).

89 Los trascendentales sectores del agua y la energía siguen en manos de los Estados, salvo en materia de contratación armonizada.
} 
En cuanto a los servicios de interés económico general, se reconoce la total discrecionalidad de los Estados (y de las autoridades regionales y locales) para prestar, hacer que se realicen y organizar servicios económicos de interés general, de acuerdo con el principio de subsidiariedad y eficacia. Declaración que supone un apoyo expreso a favor de las políticas descentralizadoras a favor de los entes locales. Sin embargo, las reservas legales en monopolio establecidas en nuestro ordenamiento a favor de los Entes Locales, en materia de servicios económicos de interés general, se verán afectadas cuando se aprueben los anunciados Reglamentos del Consejo Europeo en materia de financiación; sin perjuicio de otras limitaciones que se establezcan en garantía de la debida congruencia entre sus finalidades y los sacrificios que imponen a los principios de libertad de establecimiento y de competencia. La libertad y discrecionalidad de los Estados para establecer estos servicios, directamente o a través de los Entes Locales, deberá convivir en el futuro con las reglamentaciones horizontales o verticales de la Unión y, sin lugar a dudas, con los anunciados Reglamentos del Consejo o del Parlamento que determinen el régimen de excepciones a la libre competencia $\mathrm{y}$ los tipos de ayudas que puedan establecerse ${ }^{90}$.

\subsection{Tratado de Funcionamiento}

El Artículo 14 del Tratado de Funcionamiento de la Unión supera los contenidos del Tratado de Niza sobre los servicios de interés general, y atribuye nuevas y mayores competencias directas a favor del Parlamento y del Consejo de la UE para determinar los principios y condiciones económicas y financieras que les permitan cumplir los cometidos asignados a los servicios de interés económico general. Las «misiones a ellos encomendados» que figuraban en el artículo 86.2 del TCEE, sirven ahora de fundamento para atribuir al Parlamento y al Consejo Europeo por el procedimiento legislativo ordinario, a propuesta de la Comisión, la definición de los principios y de las condiciones económico-financieras de los servicios de interés económico general, que pasan a ser materia de competencia exclusiva de la Unión, protegida por el procedimiento legislativo ordinario. Sólo podrán desarrollarse por Reglamentos del Consejo o del Parlamento:

«Sin perjuicio del artículo 4 del Tratado de la Unión Europea y los artículos 93, 106 y 107 del presente Tratado, y a la vista del lugar que los servicios de interés económico general ocupan entre los valores comunes de la Unión, así como de su papel en la promoción de la cohesión social y territorial, la Unión y los Estados miembros, con arreglo a sus competencias respectivas y en el

\footnotetext{
90 Artículo 74. 3 del Anteproyecto de Ley Básica del Gobierno y la Administración Local, de mayo de 2006: Se declara la reserva a favor de los municipios de las siguientes actividades o servicios esenciales: abastecimiento y depuración de aguas; recogida, tratamiento y aprovechamiento de residuos urbanos; transporte público urbano de viajeros; alumbrado público y pavimentación de vías públicas. La efectiva ejecución de estas actividades en régimen de monopolio requiere la aprobación provisional por el Pleno municipal y la definitiva por el órgano de gobierno de la Comunidad Autónoma.
} 
ámbito de aplicación de los Tratados, velarán por que dichos servicios actúen con arreglo a principios y condiciones, en particular, económicas y financieras, que les permitan cumplir su cometido ${ }^{91}$. El Parlamento Europeo y el Consejo establecerán dichos principios y condiciones mediante reglamentos con arreglo al procedimiento legislativo ordinario ${ }^{92}$, sin perjuicio de la competencia que incumbe a los Estados miembros, dentro del respeto a los Tratados, para prestar, encargar y financiar dichos servicios» ${ }^{93}$.

La nueva regulación de los servicios de interés económico general establece, en definitiva, una competencia compartida entre la Unión y los Estados. La iniciativa para establecer, prestar y regular todo tipo de servicios de interés general corresponde a los Estados, que deberán procurar se presten lo más cercanos a los ciudadanos, - el artículo 14 reproduce lo dispuesto en el Proyecto de Constitución «Sin perjuicio de los artículos III-55, III-56 y III-136, y a la vista del lugar que los servicios de interés económico general ocupan, como servicios a los que en la Unión todos conceden valor, así como de su papel en la promoción de la cohesión social y territorial de ésta, la Unión y sus Estados miembros, con arreglo a sus competencias respectivas y en el ámbito de aplicación de la Constitución, velarán por que dichos servicios actúen con arreglo a principios y condiciones, económicos y financieros en particular, que les permitan cumplir su cometido. Dichos principios y condiciones se definirán mediante leyes europeas-», con la obligada supresión de la referencia a la Ley comunitaria, que el TFUE reconduce al procedimiento legislativo ordinario, asumiendo así la posición del Libro Verde favorable al reconocimiento de un mayor papel de las Instituciones de la Unión Europea en la definición de los servicios de interés económico general.

El Consejo y el Parlamento quedan encargados de definir unas condiciones de financiación de los servicios de interés económico general que mantengan

91 Artículo 4. 1. De conformidad con lo dispuesto en el artículo 5 toda competencia no atribuida a la Unión en los Tratados corresponde a los Estados miembros.

2. La Unión respetará la igualdad de los Estados miembros ante los Tratados así como su identidad nacional, inherente a las estructuras fundamentales políticas y constitucionales de éstos, también en lo referente a la autonomía local y regional. Respetará las funciones esenciales del Estado, especialmente las que tienen por objeto garantizar su integridad territorial, mantener el orden público y salvaguardar la seguridad nacional. En particular, la seguridad nacional seguirá siendo responsabilidad exclusiva de cada Estado miembro.

3. Conforme al principio de cooperación leal, la Unión y los Estados miembros se respetarán y asistirán mutuamente en el cumplimiento de las misiones derivadas de los Tratados. Los Estados miembros adoptarán todas las medidas generales o particulares apropiadas para asegurar el cumplimiento de las obligaciones derivadas de los Tratados o resultantes de los actos de las instituciones de la Unión.

92 La exclusión de la regla de la unanimidad facilitará la aprobación de unas condiciones de general aplicación en todos los Estados. Lo que sin lugar a dudas corregirá la tendencia a la dispersión y al casuismo que está implícita en la libre y discrecional iniciativa estatal para prestarlos (gestión directa o indirecta) o para reglamentarlos con la técnica del servicio universal.

93 Evidentemente, la vigilancia sobre el cumplimiento de los principios de Derecho comunitario y la vigilancia sobre el cumplimiento de los Reglamentos que se aprueben por el Consejo o el Parlamento en los servicios de interés económico general corresponde a la Comisión. 
un grado mínimo de eficacia, así como los niveles de excepción total o parcial a la libre competencia. Podrán establecer los ámbitos territoriales, las materias competenciales y los sectores económicos que, por su mayor o menor trascendencia en relación con los intercambios comerciales y con los movimientos de capital, admitan distintos regímenes de ayudas públicas, en función del régimen de financiación que se establezca en cada caso. Los criterios del Pacto de Crecimiento y Estabilidad también están en el origen de esta atribución de competencia a favor del la Unión, que al igual que puede establecer el nivel mínimo de autofinanciación para que una sociedad se considere de mercado, en ésta materia podrá reconocer y mantener los monopolios municipales, sin perjuicio de señalar unos porcentajes mínimos de auto-financión ${ }^{94}$. A tal efecto, la Comisión podrá utilizar la información que tienen que suministrar los Estados por imperativo de la nueva Directiva sobre transparencia, que se configura como una valiosa herramienta, a la hora de fundamentar la iniciativa legislativa que establezca las reglas de financiación de los servicios de interés económico general en todo el ámbito de la Unión Europea.

\subsection{Protocolo sobre los servicios de interés económico general}

Artículo 1. «Los valores comunes de la Unión con respecto a los servicios de interés económico general con arreglo al artículo $14^{95}$ del Tratado de Funcionamiento de la Unión Europea incluyen en particular»:

- El papel esencial y la amplia capacidad de discreción de las autoridades nacionales, regionales y locales para prestar, hacer que se realicen y organizar los servicios de interés económico general lo más cercanos posible a las necesidades de los usuarios;

- la diversidad de los servicios de interés económico general y la disparidad de las necesidades y preferencias de los usuarios que pueden resultar de las diferentes situaciones geográficas, sociales y culturales;

- un alto nivel de calidad, seguridad y accesibilidad económica, la igualdad de trato y la promoción del acceso universal y de los derechos de los usuarios.

\footnotetext{
94 En última instancia, el servicio de interés económico general es un instrumento al servicio de la Administración para ejercer la iniciativa económica en materia de necesidades esenciales que no se puede satisfacer con el recurso al mercado En cualquier caso las responsabilidades de su equilibrio financiero y de su régimen económico corresponden a la Administración que lo tutela, que tendrá que pechar con su déficit en términos SEC. Sin duda será por la vía de las normas sobre cómputo de su endeudamiento, por donde pueda llegar una normativa comunitaria que controle la financiación de los servicios de interés económico general.

95 Las altas partes contratantes, deseando enfatizar la importancia de los servicios de interés general, han convenido en las siguientes disposiciones interpretativas, que se incorporarán como anexo al Tratado de la Unión Europea y al Tratado de Funcionamiento de la Unión Europea.
} 
Artículo 2: «Las disposiciones de los Tratados no afectarán en modo alguno a la competencia de los Estados miembros para prestar, hacer que se realicen y organizar servicios de interés general que no sean económicos» ${ }^{96}$.

Se mejoran las declaraciones y mandatos de los artículos 16 del Tratado de Niza y 36 de su Carta anexa. Cuando entre en vigor definitivamente este Tratado de Lisboa, tras la repetición acordada para el referendum en Irlanda o según la fórmula que se acuerde, sus mandatos de calidad, seguridad, accesibilidad, igualdad de trato, y la misma conveniencia de organizar los servicios lo más cerca posible de los ciudadanos, accederán a la categoría de nuevos principios de Derecho comunitario, que sin ningún genero de dudas, podrán alegarse a la hora de recurrir las decisiones y los acuerdos de todos los poderes públicos de los distintos Estados en materia de establecimiento, modificación y ampliación de las distintas prestaciones de los servicios económicos de interés general, para demandar la aplicación de estos principios de igualdad, calidad, y universalidad que, junto con la diversidad, gozan ahora de la primacía del Derecho comunitario originario sobre el Derecho nacional ${ }^{97}$.

En cuanto a su alcance y contenido político, es evidente que no se opta por una línea o posición concreta, que favorezca a unos u otros partidos; por el contrario, el reconocimiento de todas las posibilidades: prestar, hacer que se realicen $u$ organizar, autoriza tanto la gestión directa (prestar) como la denominada regulación del servicio universal (hacer que se realicen), pasando por todo tipo de fórmulas intermedias de gestión indirecta y de gestión compartida, según la libre decisión que adopte el Gobierno de cada Estado.

\section{LOS EFECTOS DEL TRATADO DE LISBOA SOBRE LA LEGISLACIÓN DE RÉGIMEN LOCAL}

\subsection{Principio de subsidiariedad y cláusula de universalidad local}

El Protocolo sobre los servicios de interés económico general del Tratado de Lisboa (PSIEG) asume las propuestas del Libro Blanco en materia de sub-

96 El Protocolo sobre los servicios de interés general aparece con el ordinal 6, justo tras los protocolos sobre los grandes y tradicionales principios de la Unión Europea:

1. Protocolo sobre el cometido de los Parlamentos nacionales en la Unión Europea

2. Protocolo sobre la aplicación de los principios de subsidiariedad y proporcionalidad

3. Protocolo sobre el mercado interior y la competencia

4. Protocolo sobre la aplicación de la Carta de Derechos Fundamentales a Polonia y al Reino Unido

5. Protocolo sobre el ejercicio de las competencias compartidas

Lo que evidencia la elevación de rango de los servicios de interés general en el nuevo TUE.

97 SSTJCE de 28 de junio de 1.978 Simmenthal (70/77, Rec. P. 1.453). TJCE de 27 de marzo de 1963, as. Da Costa - 28 a 30/62, Rec. P. 75; y Cilfit, de 6 de octubre de 1982. El juez nacional puede hacer un juicio positivo de validez, pero nunca lo puede hacer negativo, STJE, asunto Foto-Frost. Será la Jurisprudencia del TJCE, como es habitual, la encargada de conceder a los derechos de la Carta la primacía del Derecho comunitario. 
sidiariedad territorial. Lo que supone un último y definitivo impulso a las grandes declaraciones y principios de la Carta Europea de la Autonomía Local, de 15 de octubre de 1985, al incluir una referencia expresa a favor de los Entes Locales (EELL), que por primera vez obtienen una mención competencial a su favor en el Derecho Comunitario originario ${ }^{98}$. De acuerdo con el artículo 3 de la $\mathrm{CEAL}^{99}$ - reconoce plena libertad a las Administraciones Locales para ejercer su iniciativa en toda materia que no esté excluida de su competencia o atribuida a otra autoridad - , se aplica ahora el mismo principio de subsidiariedad en materia de servicios económicos de interés general, que se deben atribuir a las autoridades más cercanas a los ciudadanos. Su retención por otras administraciones superiores (Estatales o Regionales) exige ahora justificación expresa, fundada en razones de la naturaleza de la tarea o por consideraciones de eficacia y economía.

Este reconocimiento a favor de una prestación de servicios lo más cercana posible a los ciudadanos es un apoyo expreso a la cláusula de universalidad competencial de los EELL, que ya no tienen que aducir razones de eficacia para justificar los intereses que aconsejen la prestación de este tipo de servicios, por lo demás habituales en el Derecho local español. Es más, constituye un título competencial expreso y directo a su favor, que goza de la primacía del Derecho comunitario, que puede y debe utilizarse en defensa de las competencias municipales, a través del recurso constitucional especial de la Autonomía Local introducido en las medidas de Reforma de la ley 7/85, de Bases del Régimen Local, por la LO 7/99 dentro de las medidas del denominado Pacto Local.

Este nuevo título competencial fundado en unos Tratados Internacionales, por los que los Estados han delegado competencias soberanas (la moneda o la política económica) en unas instituciones comunes, forzará a una reconocimiento de una creciente relevancia constitucional en la doctrina de nuestro Tribunal Constitucional; al mismo tiempo que se superpone a la ya tradicional discusión entre el Estado y las Comunidades Autónomas sobre la necesidad de

\footnotetext{
98 Francisco Velasco CABALlero «Subsidiariedad y Competencia en la Reforma de los Entes Locales». Revista de Estudios Locales, pág. 53, COSITAL núm. Especial, julio 2005, Madrid. El principio de subsidiariedad, en su doble vertiente de proximidad y de eficacia, así como los criterios de flexibilidad en la atribución de las competencias municipales, se postulan como rectores de todo el sistema de atribución de competencias a los entes locales en el Libro Blanco. Deben formar parte del concepto de bases del Régimen Local y tener, en consecuencia, general aplicación, de tal manera que, como principio político jurídico básico, resulte exigible de la legislación sectorial de las CCAA, recuperando el carácter de canon de constitucionalidad, más allá de ese mínimo que asegura la garantía institucional ex artículo $137 \mathrm{CE}$.

99 Art. $3 .^{\circ}$ Concepto de la autonomía local: 1. Por autonomía local se entiende el derecho y la capacidad efectiva de las Entidades locales de ordenar y gestionar una parte importante de los asuntos públicos, en el marco de la Ley, bajo su propia responsabilidad y en beneficio de sus habitantes.
}

4. Las competencias encomendadas a las Entidades locales, deben ser normalmente plenas y completas. No pueden ser puestas en tela de juicio ni limitadas por otra autoridad central o regional, más que dentro del ámbito de la Ley. 
mantener la naturaleza bifronte de la Autonomía Local ${ }^{100}$ - y los títulos competenciales del Estado para establecer las bases locales, STC 240/2006-, o sobre la conveniencia de su interiorización por las Comunidades Autónomas, como se defiende desde otras posiciones doctrinales ${ }^{101}$, que se ha llevado en parte a la práctica en el Estatuto para Cataluña, aprobado por LO 6/2006. En principio, tanto el Legislador Básico como el Autonómico - cualquiera que sean sus respectivos ámbitos competenciales en Régimen Local - deberán respetar el mandado del PSIEG a la hora de atribuir los servicios económicos de interés general a favor de los Entes Locales. Lo que favorece la definitiva ejecución de la tan discutida segunda descentralización española, que cuenta así con un apoyo jurídico-político que conlleva el rango de norma de Derecho Comunitario originario, que enlaza y da mayor sentido y alcance a la Carta Europea de la Autonomía Local ${ }^{102}$.

La nueva regulación viene a ratificar y confirmar las propuestas de atribución competencial que figuraban en el Libro Blanco para la Reforma del Gobierno Local, y el fallido anteproyecto de Ley del Gobierno Local de mayo de 2006, que junto con el establecimiento de un sistema de listado competencial más amplio y con referencias expresas a potestades normativas, ya incorporaba los nuevos principios de la Carta Europea de la Administración Local para fundamentar un poder normativo autónomo Local. Ahora, la aplicación y efectividad del principio de subsidiariedad - formulado en el Derecho comunitariosupera la discusión sobre su alcance interno, limitado en su aplicación a las relaciones entre los Estados y la Unión, y sirve de principio normativo y de directriz obligatoria en la asignación de competencias a los EELL por la legislación sectorial del Estado y de las CCAA, para que, con los principios de proximidad, eficacia y proporcionalidad, justifique y obligue al reconocimiento de mayores atribuciones competenciales a los Gobiernos Locales en materia de servicios de interés económico general en la Reforma de las Bases Locales del Estado, y en las Leyes sobre Régimen Local de las CCAA, que deben reconocer un poder normativo autónomo, a ejercer por los Entes Locales dentro de un encuadramiento normativo mínimo.

\footnotetext{
100 STC 84/1982, de 23 de diciembre, apoyándose para ello en que el «carácter bifronte del régimen jurídico de las autonomías locales hace imposible calificarlo, de forma unívoca, como «intracomunitario» « extracomunitario», no es contradictorio con la naturaleza que a las entidades locales atribuye la Constitución, cuyo art. 137 concibe a municipios y provincias como elementos de división y organización del territorio del Estado»

101 FONT I LLOVET: «Porque de lo que no cabe duda alguna es de que la tendencia general de las reformas estatutarias consiste, precisamente, en «estatutorizar» - valga la expresión- en mayor o menor medida, el gobierno local, es decir, elevar a rango estatutario, como se ha dicho, la regulación sustantiva del «régimen local», lo que redunda, por un lado, en una mayor garantía frente al legislador de la posición de los entes locales». Lo que justifica así: «por un lado, cabe plantearse la virtualidad del título material «régimen local», inexistente en el artículo 149.1 de la CE, y reconducido al mismo por la jurisprudencia constitucional, por vía de su inclusión en «las bases del régimen jurídico de las administraciones públicas» del número 18. $Y$ ello, en virtud de las remisiones que los propios estatutos efectúan.
}

102 Jose Ramón PARADA VAZQUEZ «la segunda descentralización: del Estado Autonómico al municipal» RAP. Núm. 172, enero-abril de 2007, CEPC, Madrid. Pags. 16 a 22. 
El reconocimiento de mayores competencias en la prestación de servicios de interés económico general por los Entes Locales constituye el verdadero sustento de la denominada segunda descentralización a favor de los entes locales, y la cuestión más debatida es la naturaleza de las ordenanzas locales. La doctrina constitucional establecida por la STC 233/99 reconoce la plena naturaleza democrático-representativa de las ordenanzas fiscales, al aprobarse por el Pleno, representación democrática y «soberana» de los ciudadanos del municipio, lo que confiere a sus ordenanzas valor superior a los reglamentos de las CCAA ${ }^{103}$. $\mathrm{Y}$, con mayor trascendencia, en la doctrina sentada en la S 132/2001 F V, que autoriza, igual que en materia fiscal, una formulación flexible del principio de Reserva de Ley para la tipificación de infracciones y sanciones en materias donde, por estar presente el interés local, existe un amplio campo para la regulación municipal, siempre que la regulación local la apruebe el Pleno del Ayuntamiento $^{104}$. Doctrina que, siempre que se considere presente un interés local preponderante, puede extenderse con matices a las reglamentaciones locales de los servicios de interés económico general. No obstante, la habilitación normativa a favor de los EELL en esta materia no puede limitarse a establecer los criterios generales abstractos, deberá entrar en la regulación de la calidad mínima, el reconocimiento del derecho de acceso, los principios generales de organización, el tipo de contraprestación, y los criterios sancionadores.

\subsection{El Protocolo de los servicios de interés económico general como canon de constitucionalidad}

En definitiva, la mención directa al principio de subsidiariedad en la prestación de los servicios de interés económico general en un Protocolo Anexo a los Tratados de la Unión, implica establecer una regla de preferencia local por el Derecho comunitario originario. De tal manera que la especial posición y preferencia del Derecho Comunitario ya no sólo se aplica a la libertad de estable-

103 STC 233/99, de 13 de diciembre, sobre la LRHL el ámbito de colaboración normativa de los Municipios, en relación con los tributos locales, era mayor que el que podría relegarse a la normativa reglamentaria estatal. Dos datos normativos consideramos entonces relevantes para llegar a aquella conclusión: que las ordenanzas municipales se aprueban por un órgano -el Pleno del Ayuntamiento- de carácter representativo (art. 22.2.d de la LBRL, y que la garantía local de la autonomía local (arts. 137 y 140 CE) impide que la ley contenga una regulación agotadora de una materia - como los tributos locales - donde está claramente presente el interés local. F. 10 c), concluimos que aquella concepción flexible de la reserva de ley tributaria - en relación con las ordenanzas fiscales- no toleraba la renuncia de la ley a todo encuadramiento normativo de la potestad tributaria local.

104 Esta flexibilidad no sirve, con todo, para excluir de forma tajante la exigencia de ley. Y ello porque la mera atribución por ley de competencias a los Municipios -conforme a la exigencia del art. 25.2 LBRL- no contiene en sí la autorización para que cada Municipio tipifique por completo y según su propio criterio las infracciones y sanciones administrativas en aquellas materias atribuidas a su competencia. No hay correspondencia, por tanto, entre la facultad de regulación de un ámbito material de interés local y el poder para establecer cuándo y cómo el incumplimiento de una obligación impuesta por Ordenanza Municipal puede o debe ser castigada. La flexibilidad alcanza al punto de no ser exigible una definición de cada tipo de ilícito y sanción en la ley, pero no permite la inhibición del legislador. 
cimiento y a la libre competencia, se extiende ahora a los principios de atribución de competencial entre las diversas instancias territoriales de distribución del poder político interno. Lo que puede desplazar o modular la aplicación de los principios constitucionales de los Estados para establecer una especie de preferencia local. Por esta vía, el Legislador estatal que redacte un nuevo y esperado anteproyecto de Ley Básica o Ley de Bases Locales dispone de un nuevo canon, que se añade a los que figuran en la propia Constitución, para fundamentar una formulación legal de la garantía institucional o constitucional de la Autonomía Local, con un mayor alcance y ambición que la establecida en la nueva doctrina constitucional inaugurada por la S 159/2001 y consolidada plenamente en la S 240/2006, que limita las competencias locales «garantizadas» a todas aquellas que puedan reconocerse en aquellos aspectos enraizables directamente en los arts. 137, 140 y $141 \mathrm{CE}$, de cuyo contenido no representen más que exteriorizaciones o manifestaciones. ${ }^{105}$ En nuestro sistema constitucional, las Bases Estatales del Gobierno y la Administración Local deben incorporar este mandato con el alcance y carácter de mínimo común normativo, y aunque el Derecho comunitario (originario o derivado) y los tratados internacionales en general, para nuestro Tribunal Constitucional no pueden constituir un título competencial autónomo y no constituyen canon de constitucionalidad de los derechos, si tienen la consideración de elementos de interpretación de los constitucionalmente proclamados (SSTC 36/91, de 14 de febrero FJ 5; 99/2004, de 27 de mayo, FJ 3; y, 110/2007, de 10 de mayo, FJ 2; y aunque «el Derecho comunitario no es en sí mismo canon o parámetro directo de constitucionalidad en los procesos constitucionales», (SSTC 132/1989, 65/1990, 28/1991, 64/1991, 111/1993); también se ha reconocido por la doctrina constitucional española, S 13/1998 FJ 4. ${ }^{\circ}$ : «la propia interpretación del sistema de distribución competencial entre el Estado y las CC.AA. tampoco se produce en el vacío (TC S 102/1995, FJ 5. $\left.{ }^{\circ}\right) »$, por lo que prestar atención a la normativa comunitaria aplicable "puede ser no solo útil, sino incluso obligado para aplicar correctamente... el esquema interno de distribución de competencias». Lo que no es más que reconocer la influencia directa de los Tratados de la UE en el régimen de distribución de competencias Estado-CCAA.

En este sentido, al igual que la Autonomía Local es configuradota de un modelo de Estado (STC 32/81), y sirve de atribución competencial al Estado (STC 214/89), el Protocolo de los SIEG es un principio de Derecho comunitario que obliga a una adecuación normativa y estructural de los Estados, que quedan emplazados a su cumplimiento, por lo que su recepción es obligada por los distintos poderes territoriales de los Estados en sus distintos ámbitos competenciales, correspondiéndole al Estado, a través de las bases normativas del Gobierno Local determinar, para todos los entes locales, los servicios mínimos,

105 Para el propio Tribunal son mayoría en el seno de la LBRL, se incardinan, desde el punto de vista competencial, en el art. 149.1.18 CE y tienen una distinta naturaleza desde el punto de vista constitucional y ordinamental» (F. 4). 
los obligatorios, y los esenciales, y ahora también los servicios de interés económico general que se le atribuyen en régimen de monopolio o de libre concurrencia a la Administración Local, y los poderes normativos o de ordenación que tal atribución conlleva necesariamente. Estableciendo las reglas y normas básicas y mínimas que enmarquen las reglamentaciones locales, sin perjuicio de la legislación de las Comunidades Autónomas que no podrá desconocer el poder normativo local.

\subsection{La garantía institucional de la Administración local y los Estatutos de Autonomía}

La garantía institucional o constitucional de los Entes locales ${ }^{106}$ se verá reforzada con la entrada en vigor del Tratado de Lisboa, que obliga como Derecho originario, a una interpretación favorable a la atribución competencial a favor de la Administración Local, y a la efectividad de los listados competenciales que se reconocen a favor de las entidades locales básicas en los nuevos Estatutos de Autonomía, que ${ }^{107}$ desde el punto de vista formal son normas estatales, puesto que el Estatuto de Autonomía, con independencia de su proceso de formación, es una Ley Orgánica de las Cortes Generales (arts. 81.1, 146, 147.3, 151), tiene la consideración de norma de cabecera de todo el ordenamiento de la Comunidad Autónoma y, de acuerdo con el artículo 28 LOTC, constituye canon de constitucionalidad ${ }^{108}$.

En este sentido, la atribución competencial directa, que se establece en el PSIEG con carácter imperativo, plantea de nuevo la discusión trascendental sobre el rango normativo que haya de darse a los Reglamentos y ordenanzas municipales que regulen la prestación de estos servicios. Cuestión que viene a resucitar la polémica sobre el rango constitucional del Reglamento Orgánico Municipal, que fuera cercenado por la STC 214/89. La regulación de la futura Ley de Bases Locales deberá abordar el rango normativo del Reglamento Local, puesto que los Estatutos reformados no reconocen competencia normativa local autónoma. El Art. 87.3 del nuevo Estatuto de Autonomía para Cataluña, reconoce un poder o normativo propio dentro del ámbito de sus competencias, pero no autoriza un poder normativo autónomo en ningún caso.

\footnotetext{
106 Jorge FERNÁNDEZ-MIRANDA FERNÁNDEZ-MIRANDA. «El principio de Autonomía Local y la posible superación de la Garantía Institucional de la Administración Local.» RAP, Núm. 175, enero-abril de 2008. (CEPC), Madrid.

107 El artículo 147.1 de la Constitución dice: «...Los Estatutos serán la norma institucional básica de cada Comunidad Autónoma y el Estado los reconocerá y amparará como parte integrante de su ordenamiento jurídico».

108 La aprobación de los Estatutos de Autonomía por Ley orgánica no constituye un simple revestimiento formal de una norma propiamente autonómica, sino la incorporación, definitiva y decisiva, de la voluntad del legislador estatal a la configuración de lo que, por su contenido, constituye la norma institucional básica de cada Comunidad Autónoma.
} 
En definitiva, la entrada en vigor del Tratado de Lisboa obligará al Estado Español en su conjunto; la nueva ley de Bases en esta materia de servicios de interés económico general en particular, debe establecer los principios normativas que enmarquen unas competencias normativas locales propias en materia de sus servicios mínimos, obligatorios y monopolizados que no puedan desplazarse por la normativa reglamentaria del propio Estado o de las CCAA, ni desconocerse por sus Leyes. Sólo así se podrá garantizar una atribución competencial real y efectiva de competencias a favor de los EELL en materia de sus servicios de interés económico general, y de los servicios mínimos y obligatorios, que no pueda desplazarse ni eliminarse por norma reglamentaria, y que haya de tenerse en cuenta por las propia Leyes estatales o autonómicas, superándose así el habitual vaciado de competencias por la legislación sectorial ${ }^{109}$.

Junto al reconocimiento de un poder normativo autónomo, los efectos del Tratado de Lisboa no deben limitarse al reconocimiento de los principios de Derecho comunitario, la lista de servicios de titularidad local debe ampliarse por la vía de una atribución competencial directa a favor de los entes locales de los, por el momento, denominados servicios complementarios en el Art. 28 de la Ley 7/85, de Bases del Régimen Local. Y con un listado que concrete el contenido y el alcance de la delegación de competencias en el ámbito del artículo 27, a los efectos de garantizar una presencia real y efectiva de los entes locales, cualquiera que sea el contenido de la legislación material y sectorial del Estado, y cada ves más de las Comunidades Autónomas.

Todo ello, sin perjuicio de atribuir la prestación de nuevos servicios de interés económico general a la Administración Local que pasarían a ser de su titularidad, ampliándose la lista de servicios mínimos y de los servicios obligatorios. Desde este punto de vista, supone también la codificación de las nuevas propuestas de la doctrina española favorables al reconocimiento de una garantía institucional de la Administración Local con un contenido más extenso del interés local que la mera pervivencia o continuidad de los entes locales ${ }^{110}$. Todo

\footnotetext{
109 Así se denuncia en el Libro Blanco para la Reforma del Gobierno Local: «La legislación básica de régimen local no ofrece una lista determinada y formal de competencias locales, efectuando una remisión a las leyes sectoriales estatales y autonómicas, que serán las llamadas a atribuir competencias, limitándose la Ley básica a establecer una serie de materias de interés local (art. 25). Esa remisión no ha obtenido un resultado satisfactorio por varias razones

110 A. FANLO LORAS, «Fundamentos constitucionales de la autonomía local. El control sobre las corporaciones locales; el funcionamiento del modelo constitucional de autonomía local», CEC, Madrid, 1990; E. MARTín MATEO y F. SOSA WAGNER, «Cincuenta años en la Administración local», RAP, núm. 150, 1999; L. PAREJO ALFONSO, «El régimen jurídico de la Administración local hoy, en El sistema político local: nuevo escenario de gobierno» (C. ALBA Y E. VANAClOCHA), ROE, Madrid, 1997; J.L. CARRo FERnÁNDEZ-VALMAYOR, «El debate sobre la autonomía municipal», núm. 147 RAP, 1998, págs. 61 y ss; E. SÁNCHEZ GOYANES, La potestad normativa del municipio español. Ordenanzas, reglamentos, planes urbanísticos, normas, El Consultor, Madrid, 2000; J. GARCía MORRILlo, «La configuración constitucional de la autonomía local, Madrid, 1996; Tomás FONT I LLOVET, «La renovación del poder local: Avances en la configuración jurídica e institucional del gobierno local», Cuadernos de Derecho Local, y L. ORTEGA, «La potestad normativa local», págs. 39-55, en Anuario del Gobierno Local 2001, Madrid; E. AJA, «Configuración constitucional de
} 
ello acompañado del reconocimiento de un espacio normativo propio, y de los apoyos financieros necesarios para estabilizar y posibilitar su prestación, de acuerdo con los anunciados Reglamentos de la UE.

\subsection{Definitiva recepción del concepto de servicio de interés económico general}

La tradicional omisión de referencias al Derecho Comunitario y del concepto de servicio de interés económico, en la legislación de Régimen Local, cambia cuando se presentó el fallido proyecto de Ley de Bases del Gobierno Local de 3 mayo de 2006. La regulación de los servicios locales, que aparece en los artículos 74 a 78, se refiere ya directamente a los servicios de interés general, para identificarlos con los prestan o regulan las entidades locales y aquella otra actividad prestacional que dichas entidades realizan o regulan, en favor de los ciudadanos, bajo la habilitación legal de la cláusula de Estado social establecida en los artículos 1.1 y 9.2 de la CE. Introduciendo expresamente los principios del servicio universal: «los servicios locales de interés general garantizan a los ciudadanos la igualdad de acceso y de trato, la continuidad en la prestación y la protección de los derechos de los usuarios.» Pudiéndose optar por configurar sus prestaciones como servicio reglamentado.

El Proyecto fallido mantenía el libre ejercicio de la iniciativa pública en materia económica en régimen de libre competencia, con el requisito de aprobación Plenaria, "que determinará la forma concreta de gestión del servicio.» El proyecto incorporaba el concepto de servicio universal tan en boga en los años de crecimiento económico transcurridos entre 1993 y 2007, y la terminología del Derecho comunitario al identificar los servicios locales con los que prestan o regulan los entes los locales y aquella otra actividad prestacional recibe las formas y denominaciones que figuraban en los libros Verde y Blanco y en el Proyecto de Constitución Europea.

La preponderancia de las tesis liberalizadoras se manifestaba con evidencia en la reducción drástica de los servicios susceptibles de prestación en monopolio; de acuerdo con las Directivas liberalizadoras desaparecían todas las referencias a la energía, servicios mortuorios, mataderos, mercados y lonjas y la posibilidad de establecer otros mediante ley del Estado o de las Comunidades Autónomas. La reserva quedaba reducida en el Anteproyecto a las siguientes actividades o servicios esenciales: «abastecimiento y depuración de aguas; recogida, tratamiento y aprovechamiento de residuos urbanos; transporte públi-

\footnotetext{
la autonomía local», en Informe sobre el gobierno local (Tomás FONT, dir.), MAP y Fundación Pi i Sunyer, Madrid, 1992; J. GARCÍA ROCA, «El concepto actual de autonomía local según el bloque de la constitucionalidad», Revista de Estudios de la Administración Local y Autonómica, n. ${ }^{\circ}$ 282, 2000. Casimiro LóPEZ «Nuevo sistema de atribución y defensa competencial de los EELL», Cuadernos de Derecho Local, $\mathrm{n}$. 15 , octubre de 2007 (Fundación Democracia y Gobierno Local).
} 
co urbano de viajeros; alumbrado público y pavimentación de vías públicas. La efectiva ejecución de estas actividades en régimen de monopolio requiere la aprobación provisional por el Pleno municipal y la definitiva por el órgano de gobierno de la Comunidad Autónoma.» Sin embargo, de acuerdo con las disposiciones del Protocolo de los Servicios de Interés Económico General, nada se opone a una mayor extensión de la posibilidad de prestación en monopolio. La nueva Ley de Bases estatales del Régimen Local que se proponga puede mantener y aún aumentar la lista vigente, siempre con la salvedad de los servicios liberalizados por las Directivas y Reglamentos de la Unión, y con la salvaguardia del principio de libertad de empresa, que no se puede obviar, tanto por su presencia constitucional, como por tratarse de un pilar esencial del Derecho comunitario.

De acuerdo con estas consideraciones, el nuevo Proyecto de Ley Estatal Básica del Gobierno y la Administración Local, en materia de servicios locales, está obligado a incorporar la regla de preferencia local, tal como figura en el Protocolo de los Servicios de Interés General y a reconocer la competencia comunitaria para establecer medidas sobre su financiación. Lo que obligará a una profunda reflexión sobre el alcance de los servicios locales de interés económico general, con la posibilidad de establecer reglas y medidas especiales en materia de financiación de los servicios monopolizados, cuya subsistencia e incluso ampliación está asegurada en los nuevos Tratados de la Unión, sin perjuicio de las responsabilidades que se exigen a las Administraciones Públicas en situaciones de crisis económica grave y profunda como la que padecemos. 